\title{
Vertical wind retrieved by airborne lidar and analysis of island induced gravity waves in combination with numerical models and in situ particle measurements
}

\author{
Fernando Chouza ${ }^{1}$, Oliver Reitebuch ${ }^{1}$, Michael Jähn ${ }^{2}$, Stephan Rahm ${ }^{1}$, and Bernadett Weinzierl ${ }^{1,3}$ \\ ${ }^{1}$ Deutsches Zentrum für Luft- und Raumfahrt (DLR), Institut für Physik der Atmosphäre, Oberpfaffenhofen, Germany \\ ${ }^{2}$ Leibniz Institute for Tropospheric Research, Leipzig, Germany \\ ${ }^{3}$ University of Vienna, Faculty of Physics, Boltzmanngasse 5, 1090 Wien, Austria
}

Correspondence to: Fernando Chouza (fernando.chouza@dlr.de)

Received: 14 December 2015 - Published in Atmos. Chem. Phys. Discuss.: 19 January 2016

Revised: 29 March 2016 - Accepted: 29 March 2016 - Published: 14 April 2016

\begin{abstract}
This study presents the analysis of island induced gravity waves observed by an airborne Doppler wind lidar (DWL) during SALTRACE. First, the instrumental corrections required for the retrieval of high spatial resolution vertical wind measurements from an airborne DWL are presented and the measurement accuracy estimated by means of two different methods. The estimated systematic error is below $-0.05 \mathrm{~m} \mathrm{~s}^{-1}$ for the selected case of study, while the random error lies between 0.1 and $0.16 \mathrm{~m} \mathrm{~s}^{-1}$ depending on the estimation method.

Then, the presented method is applied to two measurement flights during which the presence of island induced gravity waves was detected. The first case corresponds to a research flight conducted on 17 June 2013 in the Cabo Verde islands region, while the second case corresponds to a measurement flight on 26 June 2013 in the Barbados region. The presence of trapped lee waves predicted by the calculated Scorer parameter profiles was confirmed by the lidar and in situ observations. The DWL measurements are used in combination with in situ wind and particle number density measurements, large-eddy simulations (LES), and wavelet analysis to determine the main characteristics of the observed island induced trapped waves.
\end{abstract}

\section{Introduction}

Large amounts of Saharan dust are transported every year across the Atlantic into the Caribbean region (e.g. Prospero, 1999; Prospero and Mayol-Bracero, 2013). The Cabo Verde and Barbados islands, located along the main Saharan dust transport path, interact with the dust advective flow through different mechanisms, including island induced gravity waves. This interaction can give place to changes in the dust sedimentation rates, the vertical mixing, and clouds formation among other effects (e.g. Engelmann et al., 2011; Savijärvi and, 2004; Cui et al., 2012).

In order to provide new insights into the different processes that affect the Saharan mineral dust during the longrange transport from the Sahara into the Caribbean, the Saharan Aerosol Long-range Transport and Aerosol-CloudInteraction Experiment (SALTRACE: http://www.pa.op.dlr. de/saltrace) took place in June and July 2013. In the framework of SALTRACE, 31 research flights were conducted between 10 June and 15 July 2013 by the DLR (Deutsches Zentrum für Luft- und Raumfahrt) research aircraft Falcon, including several flights in the Cabo Verde islands region and Barbados. The payload deployed on board the Falcon included a DWL (Doppler wind lidar), aerosol, temperature, humidity and wind speed in situ sensors, and dropsondes. The measurement data set generated during the SALTRACE campaign provides a good opportunity to study the generation of gravity waves by the Cabo Verde islands and Barbados and their interaction with the Saharan dust during its transport. 
Although it is well known that gravity waves can be generated by orography (Smith, 1980; Alexander and Grimsdell, 2013) and thermal effects (e.g. Baik, 1992; Savijärvi and Matthews, 2004), the relative impact of these two mechanisms depend on the specific island topography, location and atmospheric conditions. During the SAMUM-2 campaign, a large-eddy simulation (LES) study was performed in the Cabo Verde region (Engelmann et al., 2011). This study showed that a flat island with the characteristics of the Santiago Island (Cabo Verde) can induce the generation of gravity waves and enhance the aerosol downward mixing, only through its heat island effect, without taking into account its orography. Another recent LES study (Jähn et al., 2016) conducted in the Barbados area also revealed the presence of island induced gravity waves on the lee side of the island and provided further insight into the dust turbulent downward mixing, cloud generation and boundary layer modification in the lee side of the island. In contrast with the previous case, the heating effect and the orography were taken into account in this case.

Although several different measurement techniques were used to analyse gravity waves (e.g. Kirkwood, et al., 2010; Kühnlein et al., 2013; Ehard et al., 2015), including, but not limited to, ground-based lidars and radars, airborne lidars and in situ sensors, balloons and satellites, the use of airborne Doppler wind lidars is unusual (Bluman and Hart, 1988). While horizontal wind measurements retrieved by airborne DWLs are frequently found in the literature (Reitebuch et al., 2001, 2003; Weissmann et al., 2005; De Wekker et al., 2012; Kavaya et al., 2014), only a few high-resolution measurements of vertical winds are reported (Kiemle et al., 2007, 2011; Emmit and Godwin, 2014). Usually, DWLs provide measurements of the relative wind speed between the instrument and the sensed atmospheric volume every second. Using a conically arranged measurement pattern and the velocity-azimuth display (VAD) technique (Reitebuch et al., 2001), three-dimensional measurements of the wind field can be retrieved based on a few tens of measurements, which corresponds to a spatial resolution on the order of a few kilometres for airborne platforms. Although this is enough to resolve the main features of the horizontal wind field, a higher spatial resolution in the vertical wind component is required to perform turbulence, eddy flux and short-wavelength gravity wave studies.

In order to increase the spatial resolution of the vertical wind retrieval, fixed downward (nadir) pointing measurements can be performed instead of the previously mentioned conical scanning pattern. This allows the retrieval of one measurement every second, which is equivalent to a spatial resolution of around 50 to $200 \mathrm{~m}$, depending on the aircraft type and speed. Nevertheless, there are some problems associated with this technique which have to be addressed to allow an accurate vertical wind retrieval.

The paper is organised as follows. Section 2 provides a brief description of the coherent DWL mounted on the Fal-
Table 1. Key parameters of the DWL.

\begin{tabular}{lll}
\hline Laser & Laser type & Solid-state Tm:LuAG \\
\hline \multirow{5}{*}{ Transceiver } & Operation wavelength & $2.02254 \mu \mathrm{m}$ \\
& Laser energy & $1-2 \mathrm{~mJ}$ \\
& Repetition rate & $500 \mathrm{~Hz}$ \\
& Pulse length (FWHM) & $400 \mathrm{~ns}$ \\
& Telescope type & Off-axis \\
& Telescope diameter & $10.8 \mathrm{~cm}$ \\
& Transmitted polarization & Circular \\
Scanner & Detected polarization & Co-polarised \\
& Type & Double wedge \\
& Material & Fused silica \\
& Sampling rate & $500 \mathrm{MHz}$ \\
& Resolution & 8 bits \\
& Mode & Single shot acquisition \\
\hline
\end{tabular}

con research aircraft of DLR during SALTRACE and an overview of the method applied to retrieve high spatial resolution vertical wind measurements. Then, in Sect. 3, the resulting data set is used in combination with in situ observations and large-eddy simulations to analyse the generation, evolution and interaction with aerosols of island induced gravity waves. Two different cases were analysed: one in the Cabo Verde region and the other in the Barbados Island. The measurements corresponding to both cases and simulation results from the second case are compared in order to determine the similarities and differences between the two cases, as well as the ability of the simulation to reproduce the observed waves and provide a context to the in situ and lidar measurements. Finally, Sect. 4 provides a summary and concluding remarks.

\section{Coherent DWL instrument}

\subsection{Instrument description}

During SALTRACE an airborne coherent DWL was deployed on board the DLR Falcon 20 research aircraft. The system, based on an instrument developed by CLR Photonics (Henderson et al., 1993), today Lockheed Martin Coherent Technologies (LMCT), was modified by DLR (Köpp et al., 2004) to provide airborne measurement capabilities. The transceiver head, holding the diode pumped solid-state Tm:LuAG laser, the $10.8 \mathrm{~cm}$ diameter afocal transceiver telescope, the receiver optics and detectors, and a double wedge scanner is mounted on the front part of the passenger cabin (Fig. 1), while the laser power supply, the cooling unit, the data acquisition and control electronics are mounted in two separated racks.

The lidar operates at a wavelength of $2.02254 \mu \mathrm{m}$, with a pulse full width at half maximum (FWHM) of $400 \mathrm{~ns}$, a pulse energy of 1-2 mJ, and a repetition frequency of $500 \mathrm{~Hz}$. The key system specifications are presented in Table 1. 


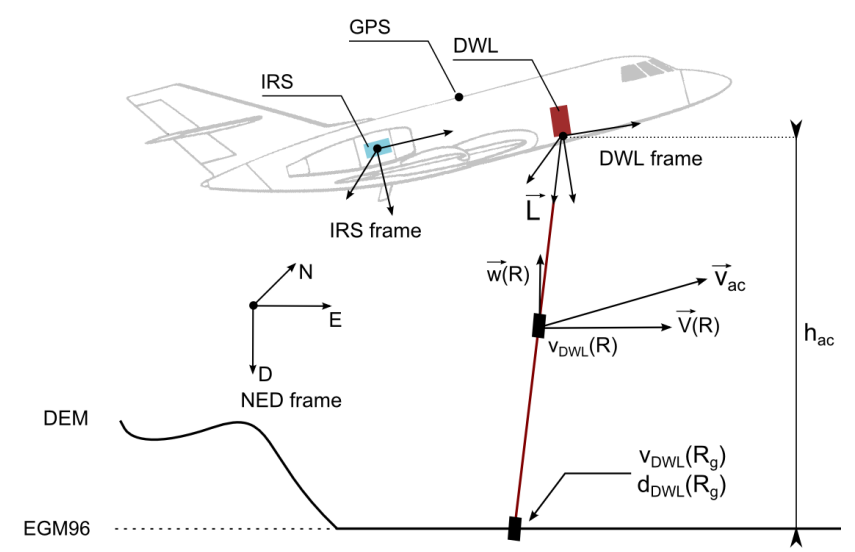

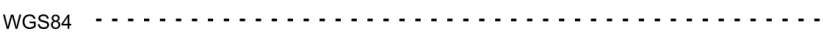

Figure 1. Scheme with the different reference frames and magnitudes involved in the vertical wind retrieval calculations. The DWL frame is a reference frame fixed to the DWL transceiver head, the IRS frame is a reference frame fixed to aircraft inertial reference system (IRS) and the NED (North-East-Down) frame is an Earth reference frame for which the $x$ axis is pointing northwards, the $y$ axis is pointing eastwards and the $z$ axis completes the righthanded reference system pointing downwards, parallel to the norm of a plane tangential to the Earth reference ellipsoid. $\boldsymbol{L}$ is a unit vector that represents the DWL line of sight (LOS), $\boldsymbol{v}_{\mathrm{ac}}$ is the aircraft speed, $\boldsymbol{V}$ and $\boldsymbol{w}$ are the horizontal and vertical wind speed respectively in a range $\mathrm{R}$ from the lidar, $v_{\mathrm{DWL}}$ is the relative speed measured by the DWL, $h_{\mathrm{ac}}$ is the aircraft altitude about ground level and $R_{\mathrm{g}}$ is the range between the lidar and the ground. WGS84 is the World Geodetic System 1984 standard used by the GPS system, while EGM96 is the Earth Gravitational Model 1996 used for correction. DEM is digital elevation model.

Based on the heterodyne technique, DWLs are able to measure the projection of the relative velocity between the lidar and wind along the laser pulse propagation direction. The backscattered atmospheric signal frequency, which was affected by the Doppler effect, is measured by mixing the backscatter signal with the laser source used to seed the outgoing sensing pulse. Because the outgoing pulse is frequency shifted by $100 \mathrm{MHz}$ with respect to the seeding laser by an acousto-optical modulator (AOM), the DWL is able to resolve the magnitude and sign of the Doppler induced frequency shift. Finally, applying the Doppler equation, the measured frequency difference can be converted to a relative speed.

As mentioned before, the DWL has a dual wedge scanner system mounted in front of the transceiver telescope. While single wedge scanners allow fixed line of sight (LOS) and conical scan patterns with a fixed off-nadir angle, dual wedge scanning systems allow the generation of arbitrary scanning patterns (Rahm et al., 2007; Käsler et al., 2010). In the case of the DLR DWL, the dual wedge scanner system consists of two independently rotating silicon wedges, with a wedge angle of $6^{\circ}$ and their flat sides arranged in parallel. Based on the vector form of the Snell's law and the angular measurements $\theta_{1}$ and $\theta_{2}$ provided by the rotary encoders attached to each wedge, the DWL pointing direction $\boldsymbol{L}_{\mathrm{DWL}}\left(\theta_{1}, \theta_{2}\right)$ can be calculated (Amirault et al., 1985).

Particularly in the case of airborne measurements, two operation modes are used: the conical step and stare and the nadir pointing mode. The step and stare mode retrieves horizontal wind speed and direction based on the previously mentioned VAD technique (Reitebuch, 2012; Weissmann et al., 2005; Reitebuch et al., 2001). The measurement pattern consists of a set of up to 24 regularly spaced pointing directions $\boldsymbol{L}_{\text {DWL }}$ distributed in a conical geometry with an accumulation time of 1 or $2 \mathrm{~s}$ for each position. On the other side, for the retrieval of vertical wind speed, the LOS vector $\boldsymbol{L}_{\mathrm{DWL}}$ is set pointing approximately in nadir direction, and the measurements are performed with an accumulation time of $1 \mathrm{~s}$. Corrections to the LOS speed resulting from a non-zero nadir angle are discussed in Sect. 2.3.

While horizontal wind speeds are about 1 order of magnitude lower than the aircraft speed (approx. $180 \mathrm{~m} \mathrm{~s}^{-1}$ ), vertical winds are usually 2 orders of magnitude lower. Because the DWLs measure relative speed between the instrument and the sensed atmospheric volume, the retrieval of the wind speed requires knowing the aircraft speed component of the measurement. This calculation requires especially accurate measurements of the aircraft speed, orientation, and DWL relative position with respect to the aircraft. A second problem associated with this measurement scheme is the projection of the horizontal wind speed. A deviation of the DWL LOS from the nadir direction introduces a projection of the horizontal wind speed in the vertical wind measurement that can be only partially corrected.

Although the vertical wind retrieval would require a constant nadir pointing LOS in order to avoid the projection of the horizontal wind speed, the system configuration during SALTRACE did not perform an automatic correction of the LOS. However, a manual adjustment of the LOS was performed during flight to partially correct the pitch angle of the aircraft. The $\boldsymbol{L}_{\mathrm{DWL}}$ vector was set with an offset angle between -2 and $-2.5^{\circ}$ around the $y$ axis to partially compensate, in combination with the DWL mounting angle, the aircraft pitch (normally between 4 and $6^{\circ}$ ).

\subsection{Calculation of the LOS pointing direction}

Based on the angles read by the scanner encoders, the output beam direction with respect to the DWL frame can be determined. Nevertheless, because the system is mounted on an aircraft which changes its orientation during the flight, additional transformations are required to relate the lidar LOS vector to an Earth-fixed reference frame.

As can be seen in Fig. 1, the DWL transceiver head is mounted on the front part of the DLR Falcon 20 research aircraft, with the transceiver telescope pointing downwards to allow the measurement of vertical profiles. The orien- 
tation of the transceiver head with respect to the aircraft frame (IRS frame) can be described by a set of Euler angles $\boldsymbol{\theta}_{\mathrm{DWL}}=\left[r_{\mathrm{DWL}}, p_{\mathrm{DWL}}, y_{\mathrm{DWL}}\right]$ which are determined by the mechanical mounting of the lidar, where $r$ is the roll angle, $p$ the pitch angle and $y$ the yaw angle. Although the magnitude of these angles is small (on the order of a few degrees), they have to be taken into account to avoid large systematic errors in the wind retrieval algorithm. A second set of Euler angles $\boldsymbol{\theta}_{\mathrm{IRS}}=\left[r_{\mathrm{IRS}}, p_{\mathrm{IRS}}, y_{\mathrm{IRS}}\right]$, measured by the IRS of the aircraft, describes the orientation of the aircraft with respect to a local NED (North-East-Down) Earth reference frame. The Falcon IRS system provides yaw angle measurements at a rate of $20 \mathrm{~Hz}$, and pitch and roll measurements at $50 \mathrm{~Hz}$. These measurements are then averaged for $1 \mathrm{~s}$ to match the DWL accumulation time.

The LOS vector $\boldsymbol{L}_{\mathrm{DWL}}$ calculated based on the angles measured by the scanner encoders can be translated to a reference frame fixed to the Earth applying the following equation

$\boldsymbol{L}=\left[\begin{array}{c}L_{\mathrm{N}} \\ L_{\mathrm{E}} \\ L_{\mathrm{D}}\end{array}\right]=\mathbf{C}_{\mathrm{NED}}^{\mathrm{IRS}}\left(\boldsymbol{\theta}_{\mathrm{IRS}}\right) \cdot \mathbf{C}_{\mathrm{IRS}}^{\mathrm{DWL}}\left(\boldsymbol{\theta}_{\mathrm{DWL}}\right) \cdot \boldsymbol{L}_{\mathrm{DWL}}\left(\theta_{1}, \theta_{2}\right)$,

where $\boldsymbol{L}$ is the LOS vector $\boldsymbol{L}_{\mathrm{DWL}}$ referred to the Earth reference system for a given aircraft orientation $\boldsymbol{\theta}_{\mathrm{IRS}}, \mathbf{C}_{\mathrm{NED}}^{\mathrm{IRS}}\left(\boldsymbol{\theta}_{\mathrm{IRS}}\right)$ is a coordinate transformation matrix between the IRS and the NED reference frames based on the IRS measurements and the $\mathrm{C}_{\mathrm{IRS}}^{\mathrm{DWL}}\left(\boldsymbol{\theta}_{\mathrm{DWL}}\right)$ is a coordinate transformation matrix between the DWL reference frame and IRS reference frame, calculated for a set of mounting angles $\boldsymbol{\theta}_{\mathrm{DWL}}$ (Grewal et al., 2007).

\subsection{Vertical wind retrieval method}

For an airborne DWL with a given pointing direction, the retrieved velocity corresponds to the relative speed, projected on the laser beam direction of propagation, between the aircraft and the atmospheric target or ground surface contained by the sensed volume at distance $R$. This relation is summarized by the equation

$v_{\mathrm{DWL}}(R)=\boldsymbol{L} \cdot \boldsymbol{v}_{\mathrm{ac}}+\boldsymbol{L} \cdot \boldsymbol{V}(R)+\boldsymbol{L} \cdot \boldsymbol{w}(R)$,

where $v_{\mathrm{DWL}}(R)$ is the speed measured by the airborne DWL, $\boldsymbol{L}$ is the beam direction of propagation or LOS, $\boldsymbol{v}_{\mathrm{ac}}$ is the aircraft speed, $\boldsymbol{V}(R)=[u(R), v(R), 0]$ and $\boldsymbol{w}(R)=$ $[0,0, w(R)]$ are the horizontal and the vertical component of the wind speed respectively. In all cases, the vectors are referred to as an Earth reference frame.

The first step in the wind retrieval process is the removal of the aircraft speed projection on the measured LOS. While accurate measurements of the aircraft speed are obtained from a GPS system mounted on the aircraft, the LOS vector $\boldsymbol{L}$ is determined based on the angle measurements of the scanner encoders, the transceiver mounting orientation and the aircraft orientation measured by the IRS.
As mentioned in the previous section, the exact transceiver head mounting angles can be derived from DWL measurements. The proposed method for the mounting angles $\boldsymbol{\theta}_{\mathrm{DWL}}$ estimation is based on surface returns. Previous studies used the fact that the land is immobile to derive alignment parameters for airborne Doppler radars (Bosart et al., 2002) and lidars (Reitebuch et al., 2001; Kavaya et al., 2014). Although this assumption is valid for the case of land returns, in the case of sea surface returns (which is the case of most surface retrievals during SALTRACE), the wind-induced movement of the surface can introduce non depreciable offsets in the retrievals. On the other side, deviations perpendicular to the flight direction are hard to resolve using only surface speed measurements because this parameter is less sensitive to rotations around the aircraft longitudinal axis (roll angle). The proposed method for the mounting orientation estimation is based on a combination of relative surface speeds and distances.

For the case of a range gate corresponding to land surface return, Eq. (2) is reduced to the following expression:

$v_{\mathrm{DWL}}\left(R_{\mathrm{g}}\right)=\boldsymbol{L} \cdot \boldsymbol{v}_{\mathrm{ac}}$.

As was mentioned in the previous section, the DWL mounting angles are small. Based on this fact, a small angle approximation can be applied to the rotation matrix $\mathbf{C}_{\mathrm{IRS}}^{\mathrm{DWL}}$ from Eq. (1), resulting in the following matrix:

$\mathbf{C}_{\mathrm{IRS}}^{\mathrm{DWL}}\left(\boldsymbol{\theta}_{\mathrm{DWL}}\right) \approx\left(\begin{array}{ccc}1 & -y_{\mathrm{DWL}} & p_{\mathrm{DWL}} \\ y_{\mathrm{DWL}} & 1 & -r_{\mathrm{DWL}} \\ -p_{\mathrm{DWL}} & r_{\mathrm{DWL}} & 1\end{array}\right)$

Then, substituting Eq. (4) in Eq. (1) and the result in Eq. (3), we can write the following linear equation:

$$
\begin{aligned}
v_{\mathrm{DWL}}\left(R_{\mathrm{g}}\right) & =\mathrm{C}_{\mathrm{NED}}^{\mathrm{IRS}}\left(\boldsymbol{\theta}_{\mathrm{IRS}}\right) \cdot\left(\begin{array}{ccc}
1 & -y_{\mathrm{DWL}} & p_{\mathrm{DWL}} \\
y_{\mathrm{DWL}} & 1 & -r_{\mathrm{DWL}} \\
-p_{\mathrm{DWL}} & r_{\mathrm{DWL}} & 1
\end{array}\right) \\
& \cdot \boldsymbol{L}_{\mathrm{DWL}}\left(\theta_{1}, \theta_{2}\right) \cdot \boldsymbol{v}_{\mathrm{ac}} .
\end{aligned}
$$

Using a set of land surface return measurements obtained by the lidar operating in conical scanning mode, an overdetermined set of linear equations can be defined. Its solution gives us an estimation of the DWL mounting orientation $\boldsymbol{\theta}_{\text {DWL }}$.

Although it is possible to estimate the mounting angles based only on land surface speed measurements, the additional use of surface distance measurements reduces the amount of required data points and increases the accuracy of the estimation, especially with respect to rotations of the transceiver head around the aircraft longitudinal axis $r_{\mathrm{DWL}}$.

For a range gate corresponding to sea surface return and neglecting Earth curvature effects, the measured distance by the lidar can be approximated by

$d_{\mathrm{DWL}}\left(R_{\mathrm{g}}\right)=\frac{h_{\mathrm{ac}}}{L_{\mathrm{D}}}$, 
where $d_{\mathrm{DWL}}\left(R_{\mathrm{g}}\right)$ is the distance measured by the lidar, $h_{\mathrm{ac}}$ is the altitude of the DWL measured by the GPS (World Geodetic System 1984 standard, WGS84) and corrected taking in account the Earth Gravitational Model 1996 (EGM96, http://earth-info.nga.mil/GandG/ wgs84/gravitymod/egm96/egm96.html), and $L_{\mathrm{D}}$ is the vertical component of the LOS vector $\boldsymbol{L}$ approximated by Eq. (5). While the use of land surface return is also possible, it requires additional processing and the use of a DEM (Digital Elevation Model). For the particular case of SALTRACE, for which most of the measurements were performed over sea, only the sea surface was used as distance reference for the estimation of the mounting orientation.

In order to characterize the stability of the mounting angles of the DWL, three different analyses were performed. First, an analysis was done based on the observation of the changes in the mounting angle for different flight conditions. For a given flight, the surface returns were grouped according to the flight altitude and the mounting angles retrieved using Eqs. (5) and (6). For altitudes below $5000 \mathrm{~m}$, the mounting angles showed a slight change with respect to those retrieved for higher altitudes. This effect can be attributed to small aircraft deformations, mounting angle variation due to the lidar flexible mounting system and the consequent change in the orientation of the lidar with respect to the aircraft IRS.

Then, a second stability analysis between different flights was performed. For each flight, surface returns (land and sea) corresponding to measurements in scanning operation mode were used to retrieve the mounting angle. Only the retrievals corresponding to flight altitudes higher than $5000 \mathrm{~m}$ and with vertical aircraft speeds lower than $0.05 \mathrm{~m} \mathrm{~s}^{-1}$ were included in the calculation. An equation system based on Eq. (5) was defined for the case of points retrieved from land surface, while Eq. (6) was used for the case of sea surface returns. For flights for which more than 50 land and sea surface return measurements were available, the equation system was solved. The results are presented in Table 2, together with the results obtained for the same flights using only one of both return types.

As can be seen in Table 2, the estimated mounting pitch angle $p_{\text {DWL }}$ does not show a big difference between both methods. This result is expected because both the distance and the ground speed measurements are strongly affected by deviations in the pitch angle. On the other hand, for the case of the roll mounting angle $r_{\mathrm{DWL}}$, the use of only one method gives place to different solutions between methods and flights, while the combination of both methods gives more stable results. The yaw angle $y_{\mathrm{DWL}}$ is better resolved by the speed measurements, which is compatible with the expected behaviour. In general, the simultaneous use of both methods gives more stable results between flights.

Finally, because the orientation showed to be stable between different flights, the same method was applied using all sea and ground surface returns which fulfill the altitude, vertical velocity and operation mode previously described, independently of the flight. The coincidence with the flight by flight calculation using distance and velocity equations is better than $0.1^{\circ}$ for pitch and yaw angles, and better than $0.2^{\circ}$ for the roll angle estimation.

The mounting orientation estimation resulting from the last calculation with all flights $\boldsymbol{\theta}_{\mathrm{DWL}}=\left[0.98,-2.08,1.62^{\circ}\right]$ was used in the horizontal and vertical wind retrieval process for all SALTRACE flight legs flown above $5000 \mathrm{~m}$. For the case of low-level flight legs $(<5000 \mathrm{~m})$ during which the aircraft deformation was relevant and surface returns are available, two different approaches can be applied to correct this effect. If the surface measurements were obtained by the lidar operating in scanning mode, it is possible to recalculate the DWL mounting orientation based on those observations. On the other hand, if the measurements were performed in nadir pointing mode, the mean difference between the surface return speed measured by the lidar $\mathrm{v}_{\mathrm{DWL}}\left(R_{\mathrm{g}}\right)$ and their estimation $\boldsymbol{L} \times \boldsymbol{v}_{\mathrm{ac}}$ can be subtracted from the retrievals corresponding to atmospheric range gates $v_{\mathrm{DWL}}(R)$ in order to partially compensate this effect.

For the particular case of vertical wind measurements, the LOS vector $\boldsymbol{L}$ has to be pointing downwards during the measurements. The better this condition is fulfilled, the better the retrieved vertical wind measurements will be. Small deviations from vertical pointing, introduces a projection of the horizontal wind speed on the LOS which cannot be distinguished from the vertical wind component. For example, for a horizontal wind speed of $10 \mathrm{~m} \mathrm{~s}^{-1}$ and a direction contrary to the flight direction, a deviation of $0.5^{\circ}$ from nadir in the pitch axis will introduce a bias of $0.09 \mathrm{~m} \mathrm{~s}^{-1}$ in the measured LOS speed.

As mentioned in Sect. 2.1, because no mounting orientation characterization was performed before the campaign and no automatic LOS correction was implemented to compensate changes in the aircraft orientation; the vertical wind measurements include the effects of the horizontal wind projection on the LOS $\boldsymbol{L} \times \boldsymbol{V}(\mathrm{R})$. To partially correct this effect, estimations of the horizontal wind speed based on DWL measurements, dropsondes and models from the same flight leg or close were used.

\subsection{Validation of method and error analysis}

In order to test and validate the method presented in the previous section, the measurements corresponding to a flight performed on 20 June 2013 were used. As a first approach, the mounting angles retrieved in the previous section were applied to estimate the surface return speed for the particular case of the leg flown between 10:31 and 10:45 LT at an altitude of $2900 \mathrm{~m}$ during which the lidar was operating in nadir pointing mode. The resulting surface speed measurements show a standard deviation of $\sim 0.4 \mathrm{~m} \mathrm{~s}^{-1}$ for sea return points and $\sim 0.1 \mathrm{~m} \mathrm{~s}^{-1}$ for land return points with a systematic difference of around $-0.4 \mathrm{~m} \mathrm{~s}^{-1}$ between the expected and the measured ground speed values. This difference, as explained 
Table 2. Estimated lidar mounting angles. The first row of each flight corresponds to the retrieved mounting angle using distance and speed measurements, while the second and third rows correspond to the use of only distance or speed respectively.

\begin{tabular}{lrrrrr}
\hline Date & $\begin{array}{l}\text { Sea surface points } \\
\text { (Distance method) }\end{array}$ & $\begin{array}{c}\text { Land surface points } \\
\text { (Speed method) }\end{array}$ & \multicolumn{3}{c}{$\begin{array}{r}\text { Estimated mounting angle } \\
{\left[{ }^{\circ}\right]}\end{array}$} \\
\cline { 4 - 6 } & & & $r_{\text {DWL }}$ & $p_{\text {DWL }}$ & $y_{\text {DWL }}$ \\
\hline 12.06 .13 & $\mathbf{5 8}$ & $\mathbf{3 0 4}$ & $\mathbf{0 . 9 1}$ & $-\mathbf{2 . 0 9}$ & $\mathbf{1 . 6 4}$ \\
\hline 18.06 .13 & 58 & - & 0.82 & -2.14 & 3.23 \\
& - & 304 & 0.66 & -2.10 & 1.61 \\
& $\mathbf{2 7 7}$ & $\mathbf{5 0 0}$ & $\mathbf{1 . 0 0}$ & $-\mathbf{2 . 0 7}$ & $\mathbf{1 . 6 3}$ \\
\hline 13.07 .13 & 277 & - & 1.31 & -2.13 & -1.94 \\
& - & 500 & 0.11 & -2.11 & 1.55 \\
& $\mathbf{6 0}$ & $\mathbf{1 3 6}$ & $\mathbf{0 . 9 9}$ & $-\mathbf{2 . 0 7}$ & $\mathbf{1 . 6 3}$ \\
\hline 14.07 .13 & 60 & - & 1.09 & -2.11 & -0.04 \\
& - & 136 & 0.89 & -2.08 & 1.63 \\
& $\mathbf{2 6 9}$ & $\mathbf{1 6 1}$ & $\mathbf{0 . 8 0}$ & $-\mathbf{2 . 1 3}$ & $\mathbf{1 . 6 4}$ \\
\hline 14.07 .13 & 269 & - & 0.20 & -2.33 & 11.52 \\
& - & 161 & 0.66 & -2.14 & 1.64 \\
& $\mathbf{5 9}$ & $\mathbf{3 9 7}$ & $\mathbf{0 . 9 2}$ & $-\mathbf{2 . 0 7}$ & $\mathbf{1 . 6 9}$ \\
\hline All flights & 59 & - & 1.13 & -2.04 & 1.82 \\
& - & 397 & 0.88 & -2.07 & 1.69 \\
& $\mathbf{5 4 0 3}$ & $\mathbf{3 4 4 9}$ & $\mathbf{0 . 9 8}$ & $-\mathbf{2 . 0 8}$ & $\mathbf{1 . 6 2}$ \\
\hline & 5403 & - & 0.99 & -2.11 & 1.37 \\
& - & 3449 & 1.00 & -2.08 & 1.62 \\
\hline
\end{tabular}

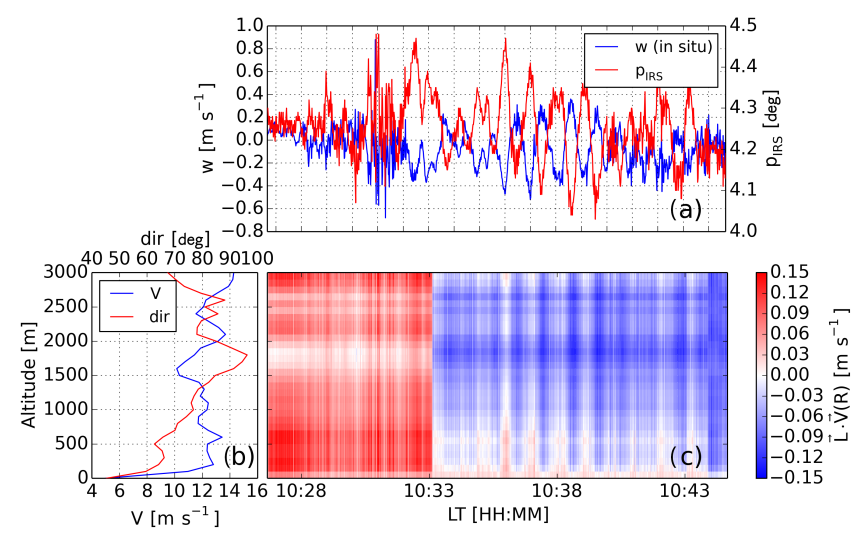

Figure 2. (a) Vertical wind speed (blue) measured by the aircraft in situ sensors at $2900 \mathrm{~m}$, together with the aircraft pitch (red). (b) Average of the horizontal wind speed (blue) and direction (red) retrieved by the DWL during a previous leg flown along the same track. (c) Projection of the horizontal wind speed to the DWL LOS due to changes in the aircraft orientation. At 10:33 LT the DWL LOS was changed by the operator in-flight to reduce the horizontal wind projection.

before, can be attributed to a change in the relative position of the lidar and the aircraft IRS due to aircraft deformations during low level flights. For this case, because measurements using scanning mode were performed during the same flight and under similar speed and altitude conditions, new mounting angles were calculated. The major difference of the recalculated values $\boldsymbol{\theta}_{\mathrm{DWL}}=\left[0.96,-2.24,1.68^{\circ}\right]$ is in the pitch angle $\left(0.16^{\circ}\right)$, which is consistent with measurements performed to analyse the stability of the mounting orientation during the flight. The recalculated mean difference between the measurements and the estimations obtained based on the new set of mounting angles is $0.036 \mathrm{~m} \mathrm{~s}^{-1}$, while the standard deviation corresponding to land and sea returns remains the same.

From the in situ vertical wind speed measurements of the Falcon nose boom sensors presented in Fig. 2a, it can be seen that the Falcon was flying through gravity waves. These waves induce a change in the aircraft pitch (Fig. 2a), which in turn induce a change in the LOS of the lidar and, therefore, a varying horizontal wind projection with a contribution between $\pm 0.15 \mathrm{~m} \mathrm{~s}^{-1}$ for a horizontal speed of $12 \mathrm{~m} \mathrm{~s}^{-1}$. In order to partially correct this feedback effect, an estimation of the horizontal wind speed and direction obtained from a previous measurement leg (10:00 to 10:15 LT) was used (Fig. 2b). The resulting projection $\boldsymbol{L} \times \boldsymbol{V}(R)$ is shown in Fig. 2c.

Finally, the vertical wind speed can be determined subtracting the aircraft speed and horizontal wind speed projections from the relative speed measured by the DWL. The re- 

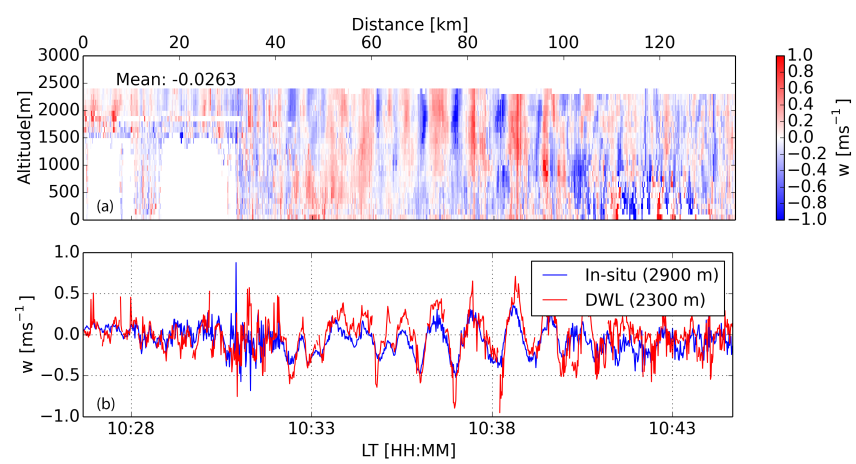

Figure 3. (a) DWL vertical wind speed retrieval for a leg flown on 20 June 13 between 10:31 and 10:45 LT. Positive (red) indicates upward winds and negative (blue) indicates downward winds. Between 10:27 and 10:31 LT the DWL coverage is limited due to the presence of clouds (white regions below $1500 \mathrm{~m}$ ). (b) Comparison between the vertical wind retrieved by the Falcon 20 (blue) for an altitude of $2900 \mathrm{~m}$ and the DWL retrieval (red) for an altitude of $2300 \mathrm{~m}$.

sulting vertical wind speeds are presented in Fig. 3a together with a comparison between the in situ vertical wind speeds measured by the Falcon (Fig. 3b). It has to be noted that the closest DWL measurements are around $500 \mathrm{~m}$ below the aircraft, which could explain the difference between the amplitude of the DWL and in situ measurements. Despite this altitude difference, the main features of the vertical wind field (amplitude, oscillation frequency and mean value) are comparable.

In order to estimate the DWL measurement error, two methods were applied. The first method (Frehlich, 2001; O'Connor et al., 2010) is based on the frequency spectrum of the retrieved velocity. For the flight leg presented in Fig. 3, the spectra corresponding to the retrieved vertical wind speed from the DWL measurements at altitude of $2300 \mathrm{~m}$ were calculated and averaged. A total of 32 spectra of 64 samples were calculated. A $50 \%$ window overlap factor, a Hanning window and a zero-padding of the missing values was applied to each window for each spectrum calculation (Kiemle et al., 2011). The resulting spectrum, presented in Fig. 4, shows that for frequencies higher than $0.2 \mathrm{~Hz}$ the spectrum corresponding to the DWL tends to be a constant value, departing from the Kolmogorov's $-5 / 3$ law. This high-frequency region represents the spectrum of the random measurement noise. The standard deviation of the measurement is then estimated as the mean of the spectra over its constant region. Based on the presented case, the random measurement error was estimated to be $\sigma_{\mathrm{e}}=0.16 \mathrm{~m} \mathrm{~s}^{-1}$.

The second method, based on ground return analysis, relies on the fact that the ground surface is not moving. For an ideal system, the difference between the ground return speed measured by the lidar and the aircraft speed projected on the beam direction has to be zero. For a real DWL, the mean of this difference corresponds to the systematic measurement

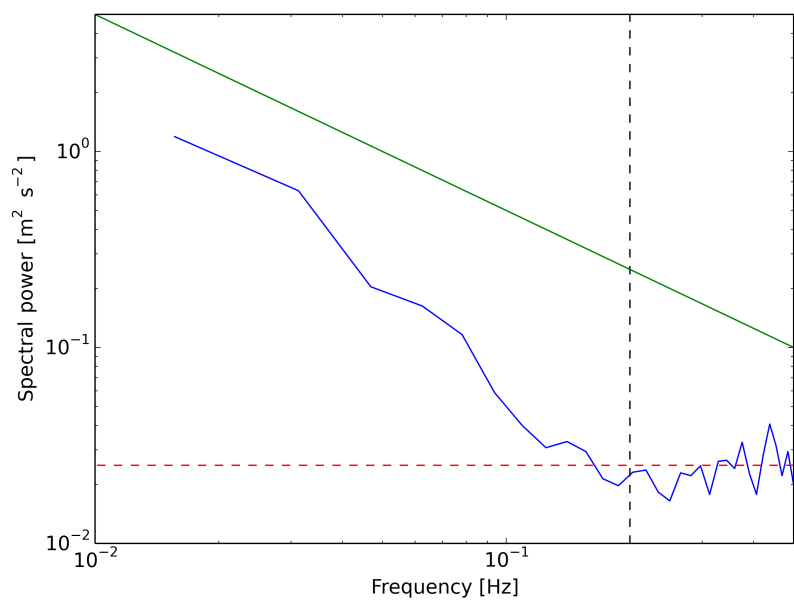

Figure 4. Spectral power for the DWL measured vertical wind speed during the flight on 20 June 2013, between 10:31 and 10:45 LT and for an altitude of $2300 \mathrm{~m}$ (solid, blue). The expected spectral behaviour according to the Kolmogorov's -5/3 law (green line), the noise frequency threshold (black, dotted) and the derived noise floor for the DWL (red, dotted) are shown.

error, while its variations correspond to the lidar random error for high SNR. Based on the land returns, the estimated systematic error is $\mu_{\mathrm{e}}=-0.05 \mathrm{~m} \mathrm{~s}^{-1}$ and random error standard deviation is $\sigma_{\mathrm{e}}=0.10 \mathrm{~m} \mathrm{~s}^{-1}$.

The errors estimated based on both approaches are on the same order of magnitude. Because the measurement error depends on many different parameters, like SNR, turbulence and flight conditions, relatively small variations in the uncertainty are expected for differing measurement situations.

\section{Case studies}

The vertical wind retrieval method presented in the previous section was applied to the DWL measurements corresponding to two SALTRACE flights during which gravity waves were observed. While the flight corresponding to the first case study took place on 17 June 2013 in the Cabo Verde region (close to the Saharan dust source), the flight analysed in the second case study was conducted in the Barbados region, where the main SALTRACE supersite was located.

\subsection{Case 1: island induced trapped lee waves in Cabo Verde (17 June 2013)}

The synoptic conditions, derived from the ECMWF EraInterim reanalysis, on the Cabo Verde islands at 12:00 UTC (11:00 LT) on 17 June 2013 are show for 1000 and $700 \mathrm{hPa}$ pressure levels in Fig. 5 (upper panels). Northerly trade winds with a speed on the order of $5-10 \mathrm{~m} \mathrm{~s}^{-1}$ are visible at the $1000 \mathrm{hPa}$ pressure level. For the $700 \mathrm{hPa}$ pressure level the wind changes to easterly direction, which is compatible with the presence of the African Easterly Jet (AEJ). 

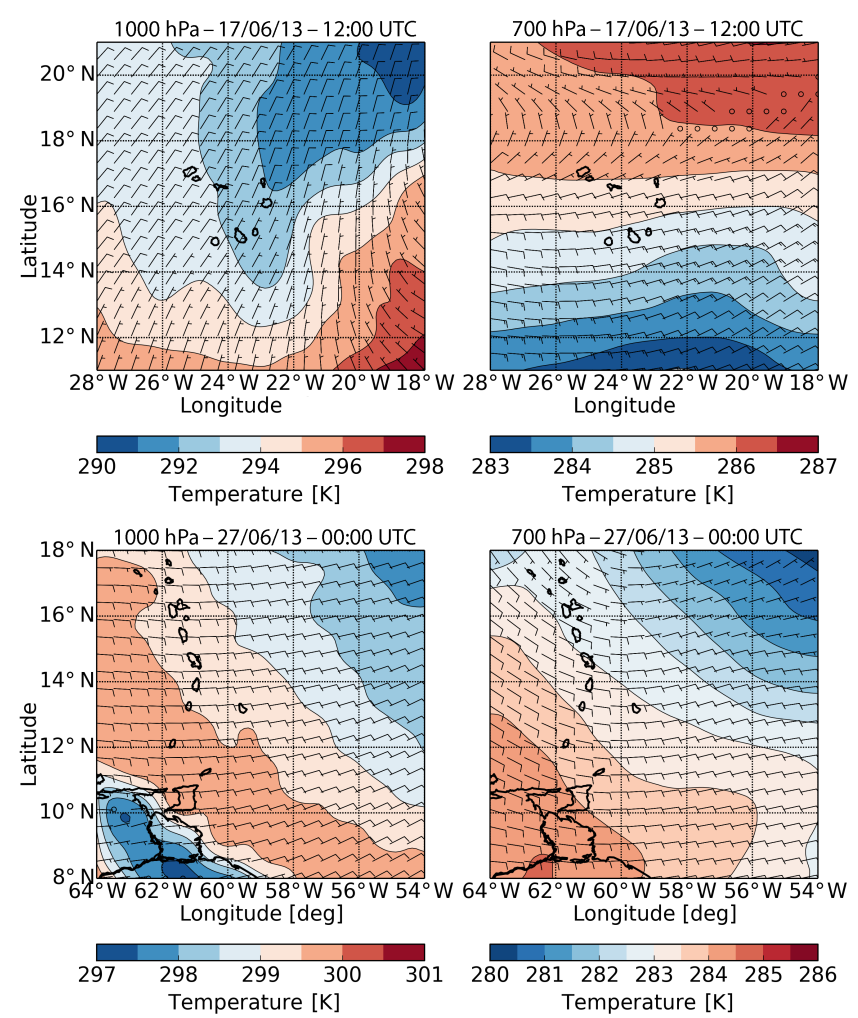

Figure 5. Synoptic conditions derived from the ECMWF ERAInterim reanalysis over the Cabo Verde islands (upper panels) and Barbados (lower panels) for the 17 and 27 June 2013 respectively. Wind vectors (barbs, in $\mathrm{m} \mathrm{s}^{-1}$ ) and temperature (in ${ }^{\circ} \mathrm{K}$ ) are shown.

During the morning of 17 June 2013, the Falcon performed a measurement flight in the Cabo Verde islands region, departing from Sal and landing on Praia (Fig. S1 in the Supplement). The flight consisted of three legs between Sal and Praia islands, at altitudes of 4100,2500 and $900 \mathrm{~m}$ respectively. During the ascent phase of the flight, the in situ sensors on board the aircraft recorded vertical profiles of potential temperature, wind speed and direction (Fig. 6a). The horizontal winds retrieved by the DWL during segments of the 1st and 2nd leg (not shown) indicate that the values retrieved by the in situ sensors are representative of the whole flight area and time period. For altitudes below $500 \mathrm{~m}$, a neutrally stratified layer with northerly trade winds can be observed. This layer is capped by a thick strongly stratified trade inversion layer (between 500 and $2000 \mathrm{~m}$ ) on which the wind direction exhibits a strong shear and a change to north-easterly direction. Above this inversion, the atmosphere shows a weak stratification and relatively constant wind speed and direction. These observations are compatible with the synoptic situation previously described.

According to linear mountain wave theory (e.g. Durran, 1990), the waves that can propagate vertically in the atmosphere can be derived by the use of the Scorer parameter $l^{2}$

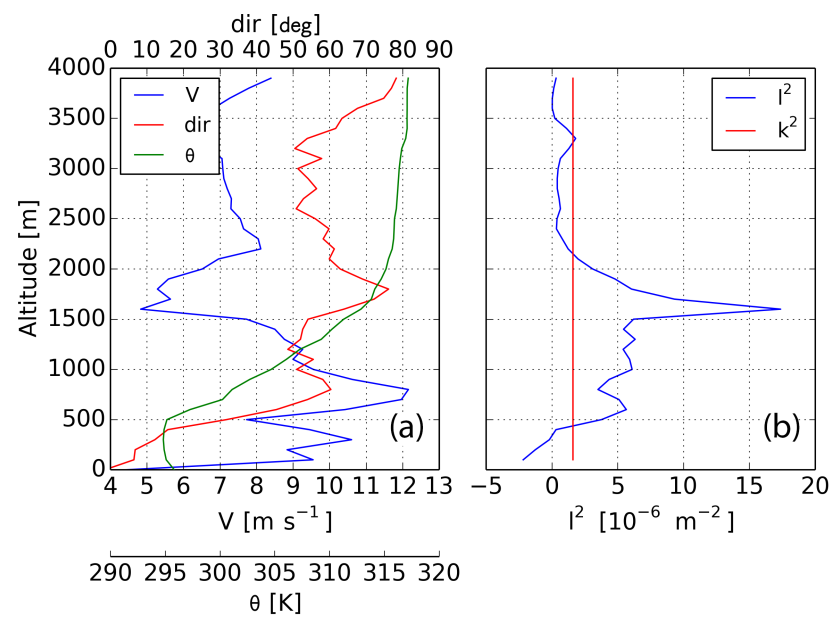

Figure 6. (a) Horizontal wind speed (blue), wind direction (red) and potential temperature (green) measured by the Falcon in situ sensors during take-off (10:06 to 10:14 LT). (b) Derived Scorer parameter (blue) and approximate wave number corresponding to the observed waves (red).

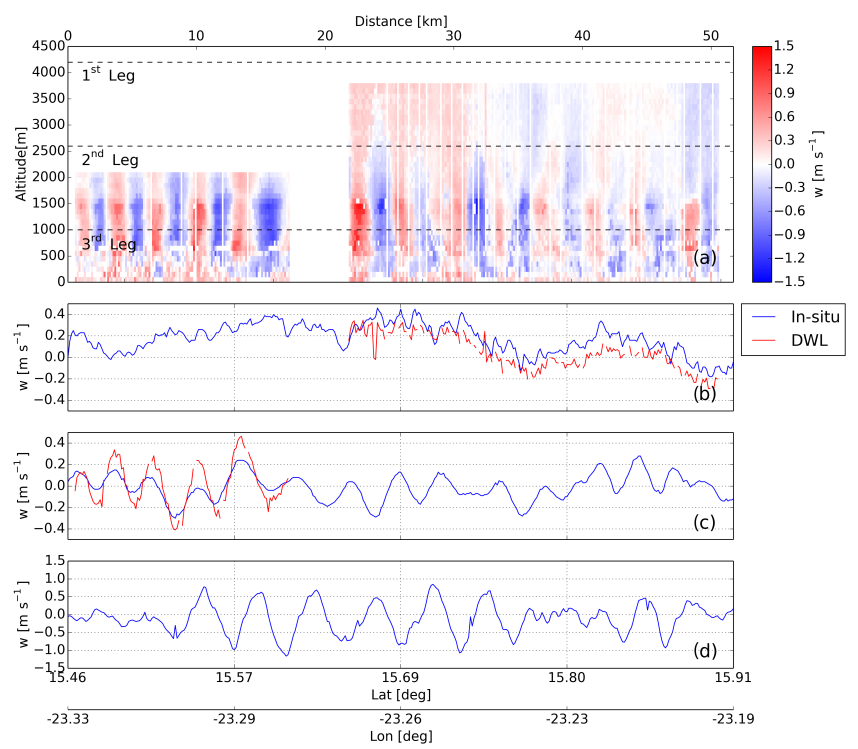

Figure 7. (a) Retrieved vertical wind speed by the DWL as a function of the latitude and longitude from legs 1 (10:21 to 10:25 LT) and 2 (10:43 to 10:46 LT), together with the flight levels corresponding to the legs 1, 2 and 3 (11:10 to 11:16 LT) (dashed lines). (b, c, d) In situ vertical wind speed corresponding to the legs 1, 2 and 3 (blue line) together with the measured wind corresponding to the uppermost range gate measured on each leg (red line).

(Scorer, 1949), given by

$l^{2}=\frac{N^{2}}{U^{2}}-\frac{1}{U} \frac{d^{2} U}{\mathrm{~d} z^{2}}$,

where $N$ is the Brunt-Väisälä frequency and $U$ is the crossmountain wind speed. Based on the previously introduced 
in situ measurements (Fig. 6a), a profile of the Scorer parameter was calculated (Fig. 6b). Since the difficulty to estimate the second derivate of the wind from real data, an approximated form of the Scorer parameter which neglects the second term (shear term) is used in this study. This simplification is allowed due to the fact that the shear term is dominated by oscillations with wavelengths much smaller than for the waves under analysis (Smith et al., 2002). An additional validation of this approximation was performed based on temperature, humidity and wind speed vertical profiles retrieved from the ECMWF ERA-Interim reanalysis presented in Fig. 5. The Scorer parameter profile calculated based on the model output and including the shear term (not shown) exhibited a similar structure to the approximated profile calculated from the Falcon in situ measurements.

According to the theory, a wave with wavelength $\lambda$ and an associated wave number $k=\frac{2 \pi}{\lambda}$ can propagate in the atmosphere if $k^{2}<l^{2}$; otherwise, the wave is evanescent. Trapped lee waves are expected when a layer with high Scorer parameter is bounded by layers with low Scorer parameter. Under such conditions, the energy of the gravity waves is mainly confined in the layer with high Scorer parameter (Durran et al., 2015). As can be seen in Fig. 6b, the conditions for the development of trapped waves are fulfilled for altitudes between 500 and $2000 \mathrm{~m}$, which are coincident with the trade inversion layer lower and upper bound.

Another important parameter to take in account for the study of lee waves is the inverse Froude number, defined as

$F=\frac{N h}{U}$,

where $N$ is the Brunt-Väisälä frequency, $h$ is the island height and $U$ is the cross-mountain wind speed. For an inverse Froude number between 0 and 0.5 , the flow behaves as described by the linear theory and waves are expected to form in the lee side of the island (Baines and Hoinka, 1985). For this case study, the Brunt-Väisälä frequency associated with the boundary layer (below $500 \mathrm{~m}$ ) is approximately $N=0.01 \mathrm{~s}^{-1}$. This situation leads, together with an inflow speed of $10 \mathrm{~m} \mathrm{~s}^{-1}$ and a maximum island height of $380 \mathrm{~m}$, to a linear flow condition $(F=0.38)$.

The DWL vertical wind measurements presented in Fig. 7a confirm the existence of trapped waves between 500 and $1500 \mathrm{~m}$. At first glance, an apparent wavelength of approximately $5 \mathrm{~km}$ and a maximum peak-to-peak amplitude of $1.5 \mathrm{~m} \mathrm{~s}^{-1}$ can be estimated from the measurements presented in Fig. 7a. Unfortunately, although the legs were flown at different altitudes, all were performed along the same track. For this reason, only the apparent wavelength can be estimated from these measurements. This apparent wavelength is always larger than the actual one and related to the angle defined between the flight track and the propagation direction of the waves. Based on the apparent wavelength, the associated apparent wave number was calculated and plotted together with the Scorer parameter profile (Fig. 6b). It can be seen that for the layer on which the trapped waves are observed, the Scorer condition for wave propagation $k^{2}<l^{2}$ is fulfilled, while, for altitudes above $1500 \mathrm{~m}$ where evanescent waves are expected $\left(k^{2}>l^{2}\right)$, the waves exhibit a strong reduction in their amplitude as a function of the altitude $\left(0.6 \mathrm{~m} \mathrm{~s}^{-1}\right.$ at $2100 \mathrm{~m}^{2}$ and $0.4 \mathrm{~m} \mathrm{~s}^{-1}$ at $2600 \mathrm{~m}$, Fig. $\left.7 \mathrm{c}\right)$.

Together with the DWL vertical winds, a set of vertical wind speed measurements was retrieved by the Falcon in situ sensors along each measurement leg (Fig. 7b, c and d). Although the vertical wind measurements from the DWL provide a better image of the vertical extension of the wave ducting, the evanescent propagation regime, and the amplitude of the waves than the in situ measurements, the DWL measurements of this case study covers only half of the 1st and one third of the 2 nd leg, limiting the spectral range that can be analysed from those measurements. In order to complement the DWL measurements and obtain a more precise picture of the spectral components and extension of the observed waves, the wavelet transform technique using a Morlet wavelet (6th order) was applied (Torrence and Compo, 1998; Woods and Smith, 2010) to the in situ vertical wind measurements of the three measurement legs. Unlike the Fourier transformation, which can only retrieve the frequency of the signal, the wavelet analysis is able to temporally resolve the frequencies of a given signal, similar to the short-time Fourier transformation. For this reason and because the measured waves are restricted to a fraction of the measurement period the wavelet analysis is more adequate than a simple Fourier transformation. The in situ measurements, acquired with a temporal resolution of $1 \mathrm{~Hz}$, were linearly interpolated to a regular spatial grid of $200 \mathrm{~m}$ resolution before applying the wavelet transformation to the acquired data sets.

Figure 8 shows the calculated spectral components corresponding to the three legs in situ vertical wind measurements. While the lower leg (Fig. 8, lower panel) exhibits one dominant spectral component with an associated apparent wavelength of $5.2 \mathrm{~km}$, the 2 nd leg (Fig. 8, mid panel) shows two spectral peaks with apparent wavelengths of 4.5 and $15.7 \mathrm{~km}$, and the 3rd leg (Fig. 8, upper panel) three peaks with apparent wavelengths of $4.5,7.53$ and $16.5 \mathrm{~km}$. Although some variability in the wavelengths is observed between legs, the modes seem to be in even-harmonic relation. The shorter mode, present in all three legs, shows a strong attenuation in the upper two legs, compatible with the evanescent propagation regime. In contrast, the longer mode, present in the upper two legs, is only slightly attenuated. Previous studies on trapped lee waves (Georgelin and Lott, 2001) showed the presence of upward propagating leaked harmonics above the wave duct. In contrast to that case, the spectral analysis of the lower leg does not show the presence of the harmonics observed in the upper two, which can be attributed to different reasons. On one side, the longer modes have wavelengths comparable to the length of the measurements leg, which limits the confidence of this observation. This limita- 


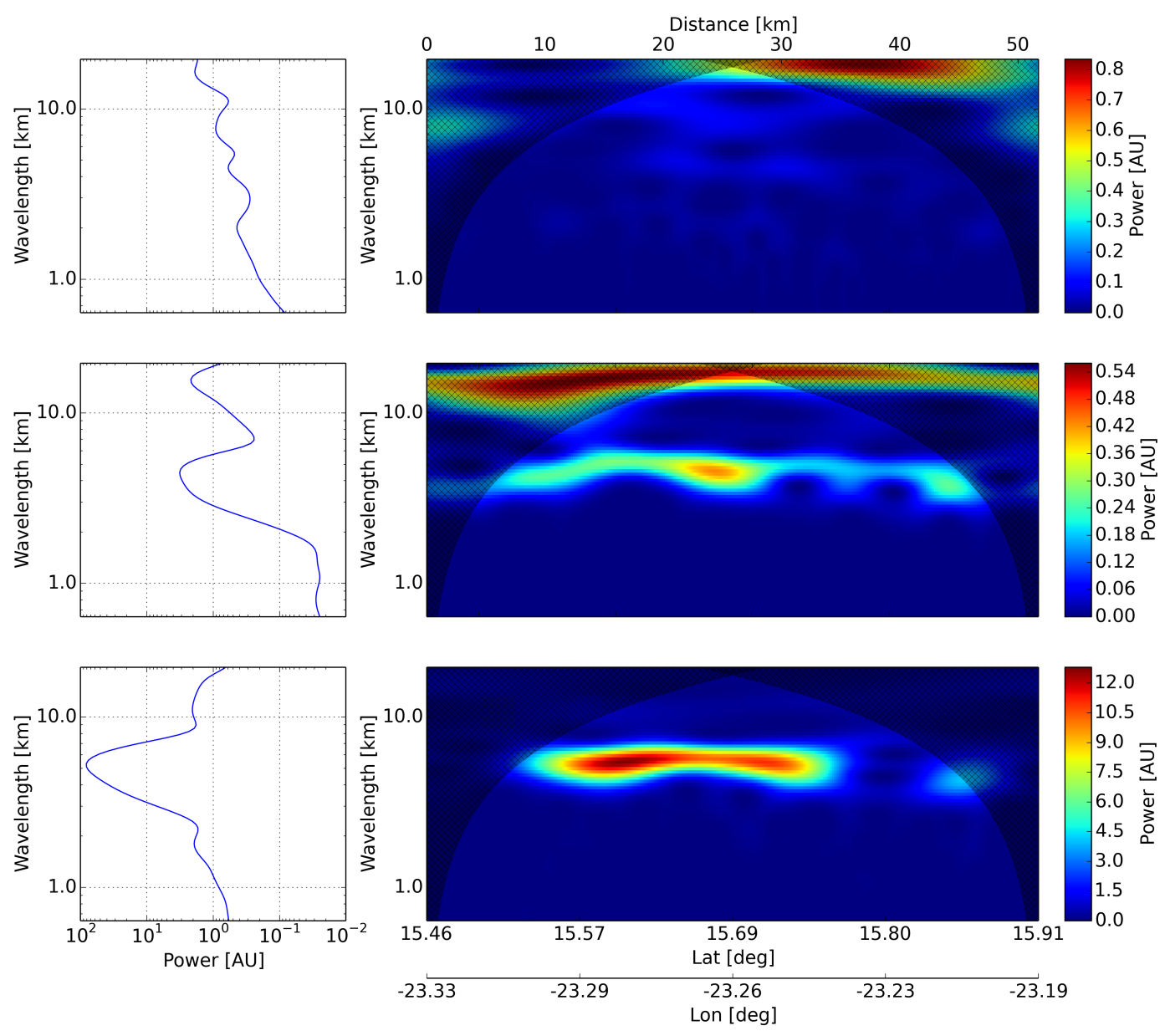

Figure 8. In situ vertical wind wavelet analysis corresponding to the three legs flown on 17 June: 1st leg (upper panels), 2nd leg (mid panels) and 3rd leg (lower panels). The hatched areas indicate the cone of influence. The left panels show the average power for each wavelength.

tion is represented by the cone of influence of the wavelet transform, which indicates the region of the wavelet spectra in which edge effects become relevant. On the other side, although the measurement legs were flown within a short time period, changes in the atmospheric conditions could have introduced a modification in the wave propagation and generation conditions. Finally, taking into account that the measurement legs extend along the downwind region of the Boa Vista and Sal islands, an interaction between waves generated by these two islands cannot be discarded.

A second point to be noted from the vertical wind in situ measurements is the change in the position of the wave crests and troughs between the measurements of the 2nd and 3rd leg, which suggest that the waves are not completely stationary.

Together with the vertical wind speed, the DWL measured the backscattered power. Range corrected backscattered power is shown in Fig. 9a together with in situ vertical winds and condensation particle counter (CPC) measurements (Weinzierl et al., 2011) for the three legs (Fig. 9b, c, d). The CPC measurements correspond to the number con- centration of particles with a diameter larger than $14 \mathrm{~nm}$. Figure 9a gives a qualitative picture of the aerosol distribution. Below $500 \mathrm{~m}$, a region of high backscatter corresponding to the marine boundary layer can be recognized. The presence of some clouds on top of the marine boundary layer is indicated by high backscatter regions. The interaction between the trapped waves, a thin aerosol layer which extends between 900 and $1300 \mathrm{~m}$, and the bottom of the Saharan Air Layer (SAL) can also be noted. The CPC measurements of the 1st and 2nd legs, corresponding to the legs flown in the SAL, show a relatively homogeneous particle number concentration along the leg, with slightly higher values in the upper one.

As the 3rd measurement leg was flown at an altitude $(1000 \mathrm{~m})$ coincident with a strong gradient in the aerosol concentration (Fig. 9a), the CPC measurements show also the effect of the waves in the aerosol distribution, but with a phase difference to the vertical wind speed of $90^{\circ}$. This explains why the waves are only visible in the third leg and not in the upper two, where the aerosol concentration gradient is close to zero. Because the aerosol vertical flux is determined by the 


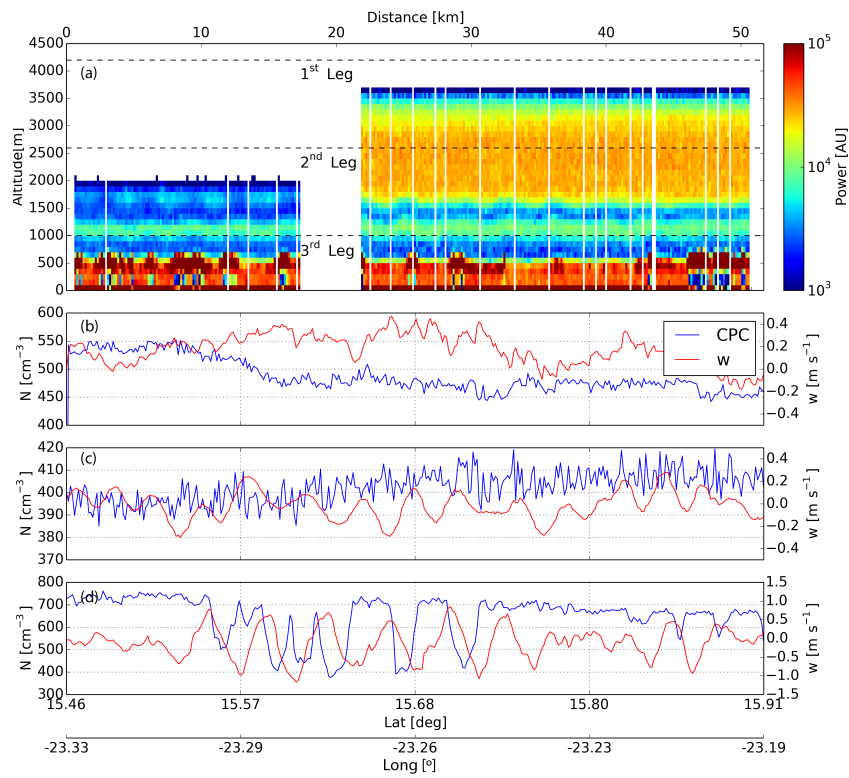

Figure 9. (a) Retrieved range corrected backscatter power by the DWL as a function of the latitude and longitude from legs 1 and 2, together with the flight levels corresponding to the legs 1, 2 and 3 (dashed lines). (b, c, d) In situ CPC measurements (blue line) corresponding to the legs 1, 2 and 3 together with the in situ measured vertical wind (red line).

integrated product of the vertical wind speed and the variation of the aerosol concentration with respect to the mean along the flight path, a phase difference of $90^{\circ}$ between these two quantities results in a zero net flux. The dust loaded air parcels periodically rise and sink without leading to a net downward or upward dust transport.

\subsection{Case 2: island induced trapped lee waves in Barbados (26 June 2013)}

\subsubsection{Measurements}

During SALTRACE several flights were conducted in the Barbados region. In this study, the measurements corresponding to the flight during the evening of 26 June 2013 are used to study the presence of island induced gravity waves in the lee side of Barbados (Fig. S2). In this case, the flight path had a cross shape centred in Bridgetown city with constant longitude (1st Leg) and latitude (2nd, 3rd and 4th Legs) at an altitude of approximately $7600 \mathrm{~m}$ for the first two legs and 3500 and $1200 \mathrm{~m}$ for the $3 \mathrm{rd}$ and 4th legs respectively.

The synoptic situation at 00:00 UTC (20:00 LT) on 27 June 2013 is show in Fig. 5 (lower panels) for 1000 and $700 \mathrm{hPa}$ pressure levels. Easterly winds with a speed of approximately $10 \mathrm{~m} \mathrm{~s}^{-1}$ can be seen at both pressure levels. Wind speed, direction and potential temperature profiles derived from a dropsonde launched at the end of the second measurement leg (Fig. S2) are presented in Fig. 10a. Below $500 \mathrm{~m}$, an al-

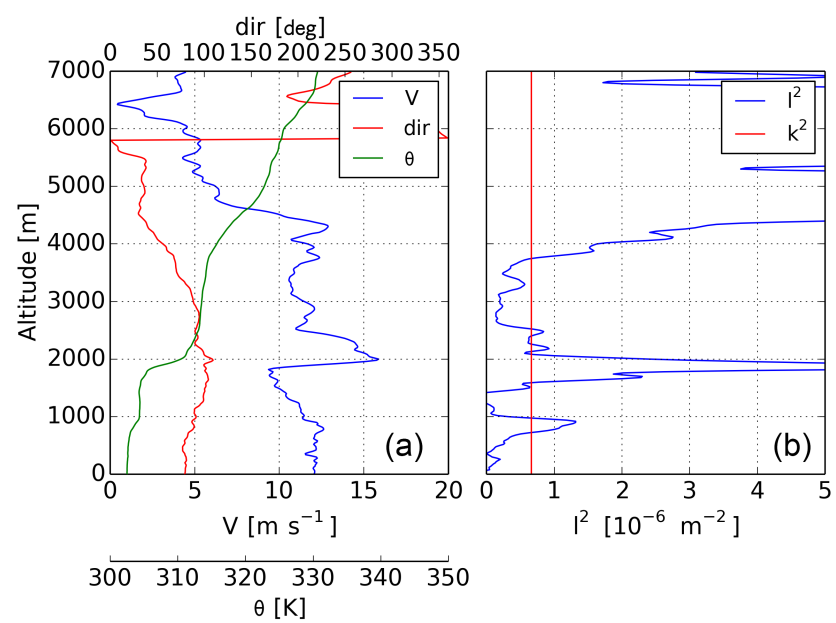

Figure 10. (a) Horizontal wind speed (blue), wind direction (red) and potential temperature (green) measured by a dropsonde launched at (26.6.13-22:05 LT). (b) Derived Scorer parameter (blue) and approximate wave number corresponding to the observed waves (red).

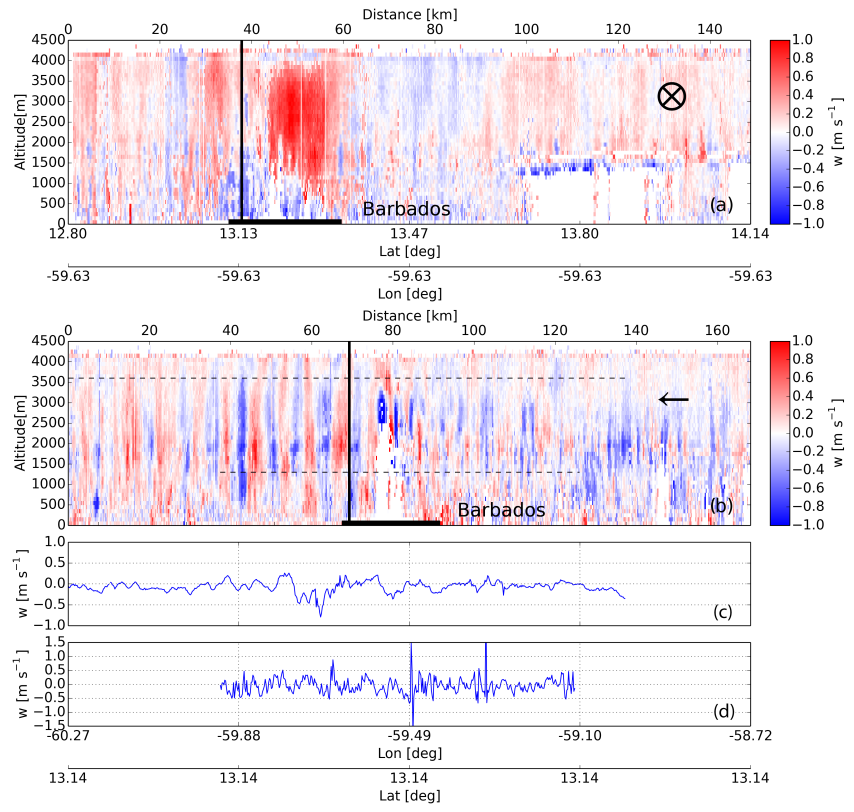

Figure 11. (a) Retrieved vertical wind speed by the DWL as a function of the latitude and longitude from leg 1 (19:53 to 20:06 LT), together with the latitude at which legs 2 (21:49 to 22:05 LT), 3 (22:16 to $22: 34 \mathrm{LT})$ and 4 were flown (22:46 to 23:01 LT) (solid line). (b) Retrieved vertical wind speed by the DWL as a function of the latitude and longitude from leg 2 , the intersection position with the 1 st leg (solid line) and the legs 3 and 4 are shown (dashed line). (c, d, e) In situ vertical wind speed corresponding to the legs 2, 3 and 4 . The average wind inflow direction is indicated on the upperright corner of panels (a) and (b). Barbados indicated in both plots with a horizontal solid black line. 


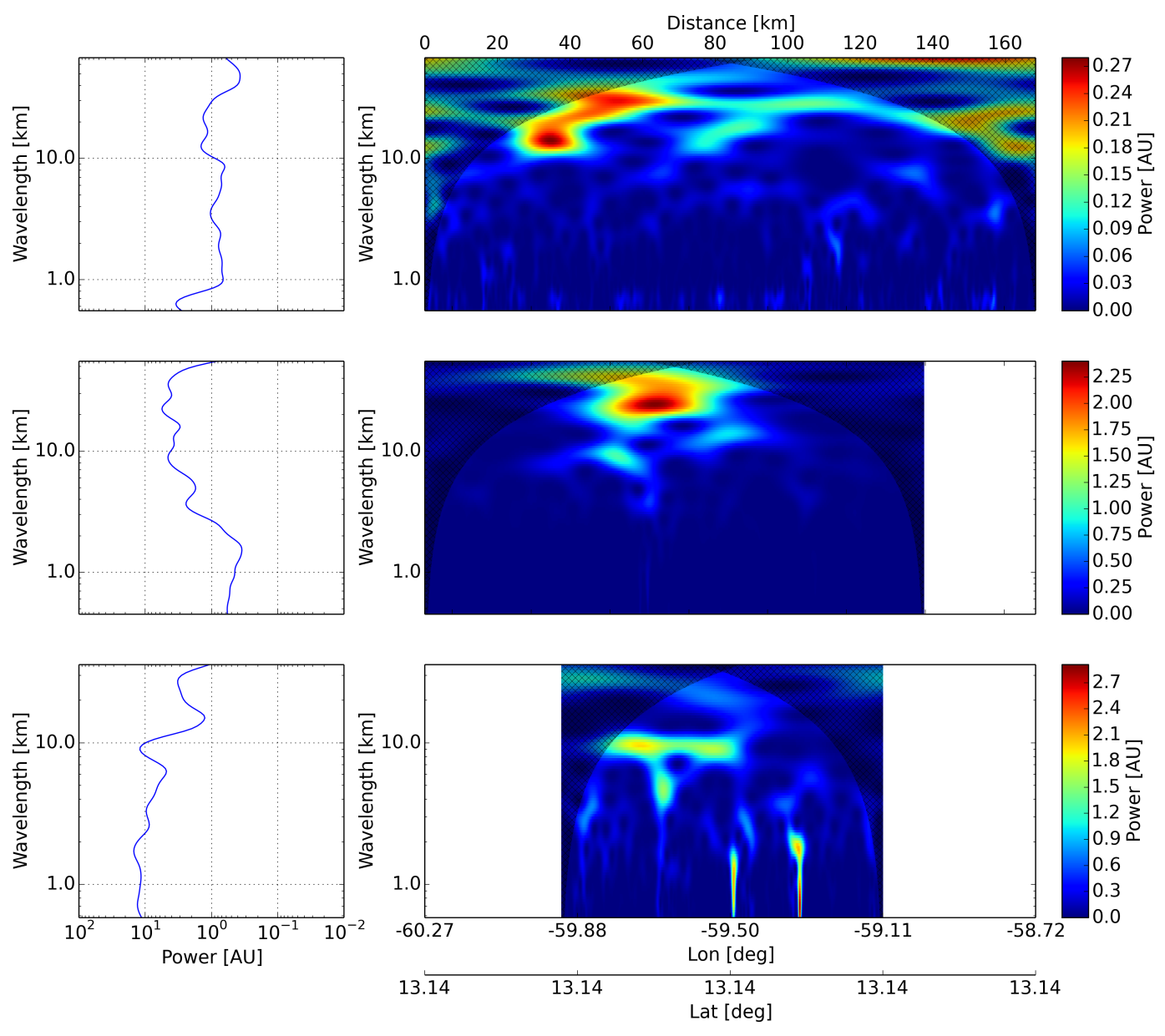

Figure 12. In situ vertical wind wavelet analysis corresponding to three legs flown on 26 June: 2nd leg (upper panels), 3rd leg (mid panels) and 4th leg (lower panels). The hatched areas indicate the cone of influence. The left panels show the average power for each wavelength.

most neutrally stratified boundary layer can be recognized, which is topped by a second neutrally stratified layer between 500 and $1800 \mathrm{~m}$. Between 1800 and $2000 \mathrm{~m}$, the sounding measurements show a thin and strong inversion $(\Delta \theta=6 \mathrm{~K})$ coincident with the lower bound of the SAL, which extends between 2000 and $4100 \mathrm{~m}$ and exhibits a typical weak stratification. Along these three layers, easterly winds with mean wind speed of $10 \mathrm{~m} \mathrm{~s}^{-1}$ are observed, while above the SAL, the stratification increases, the wind speed reduces and the direction reverses. Based on these measurements, the vertical profile of the Scorer parameter in its approximated form (Fig. 10) was calculated. As in the previous case, these measurements were compared to the DWL horizontal wind retrieval and the ECMWF ERA-Interim reanalysis results (not shown) to confirm the representativeness of the measurements.

As expected, the calculated Scorer profile shows a thin layer of high Scorer parameter corresponding to the strong inversion shown at $2000 \mathrm{~m}$, upper bounded by a low Scorer parameter layer which extends up to $3800 \mathrm{~m}$ and is associated with the weak stratification of the SAL. Trapped waves at the density discontinuity associated with the inversion at $2000 \mathrm{~m}$ are likely to occur in such conditions (Vosper, 2004; Sachsperger et al., 2015). Above the SAL, the Scorer parameter increases due to a decrease in the wind speed and a stronger stability of the atmosphere. The increase in the Scorer parameter can lead to the presence of some wave leakage into the upper layers. Because the boundary layer is very weakly stratified, the inverse Froude number is likely to be very close to zero. Based on the dropsonde observations, the Brunt-Väisälä frequency at the boundary layer was estimated to be $N=0.0025 \mathrm{~s}^{-1}$ and the cross mountain wind speed approximately $12 \mathrm{~m} \mathrm{~s}^{-1}$, which together with a maximum island height of $340 \mathrm{~m}$ gives place to $F=0.07$, suggesting a linear flow condition.

These expectations were confirmed by the DWL observations, which showed the presence of trapped lee waves on the lee side of Barbados (Fig. 11). The vertical winds measured by the DWL during the first leg (Fig. 11a) show a strong updraft with $1.2 \mathrm{~m} \mathrm{~s}^{-1}$ on the north part of Barbados, which is compatible with a measurement along a crest of the trapped waves. The 2nd leg (Fig. 11b) supports this observa- 
tion, showing a wave structure on the lee side, with a wavelength of approximately 9 to $10 \mathrm{~km}$ and a vertical extension between $500 \mathrm{~m}$ and the top of the SAL. Unfortunately, the low aerosol load above the top of the SAL $(4100 \mathrm{~m})$ limits the DWL coverage and the possibility to confirm the leakage by direct lidar measurements. The maximum amplitude (up to $3 \mathrm{~m} \mathrm{~s}^{-1}$ peak to peak) of the waves is found at an altitude of around $2000 \mathrm{~m}$, coinciding with high Scorer parameter layer, the temperature inversion and the maxima in the wind shear altitude. Above and below the inversion, the wave amplitude decrease, which is compatible with the evanescent wave regime $k^{2}>l^{2}$ observed in the Scorer parameter plot (Fig. 10b).

Although in this case the DWL measurement leg is long enough to resolve the spectra of the observed waves below the top of the SAL, the low aerosol load limits the DWL coverage in the upper part of the troposphere. For this reason, a wavelet transform was applied to the in situ vertical wind measurements of the 2nd, 3rd and 4th legs in order to determine the spectra of the waves and whether or not there is leakage of the wave into upper layers (Fig. 12). The spectra of the in situ vertical wind measurements at $7745 \mathrm{~m}$, corresponding to the 2nd leg (Figs. 11c and 12, upper panel), does not show signs of a spectral component with a wavelength around $9 \mathrm{~km}$, suggesting that this propagation mode does not leak into upper layers and that the wave dissipation is dominated by the boundary layer absorption and dispersion (Durran et al., 2015). This finding is compatible with the relatively short wavelength of the observed wave, which leads to a strong vertical decay in the evanescent wave regime regions.

The spectral analysis corresponding to the 3rd and 4th legs (Fig. 12, mid and lower panel) indicate the presence of a spectral component of the same wavelength than the observed by the lidar during the 2nd leg $(9.5 \mathrm{~km})$, but with much lower amplitude. Although this change is unexpected due to the short time difference between the 2nd leg (21:49 to $22: 05 \mathrm{LT})$ and the $3 \mathrm{rd}$ leg $(22: 16$ to $22: 34 \mathrm{LT})$, relatively small changes in the atmospheric stability conditions could have occurred in the time interval between both measurements, leading to a change in the waves propagation condition.

Together with vertical wind measurements, calibrated backscatter coefficient profiles (Fig. 13a and b) were retrieved from the DWL measurements (Chouza et al., 2015) for the 1 st and 2 nd leg. A three-layer structure can be recognized in this case, with the marine boundary layer below $500 \mathrm{~m}$, a mixed layer between 500 and $2000 \mathrm{~m}$, and the SAL between 2000 and $4100 \mathrm{~m}$. On the $2 \mathrm{nd} \mathrm{leg,} \mathrm{a} \mathrm{wave} \mathrm{structure}$ can be identified in the boundary between the SAL and the mixed layer at an altitude of $2000 \mathrm{~m}$ on the lee side of Barbados (Fig. 13b). Because the 3rd and 4th legs were flown at altitudes where the gradient in the aerosol concentration was very low, no signature of waves is observed in this case (Fig. 13c and d).
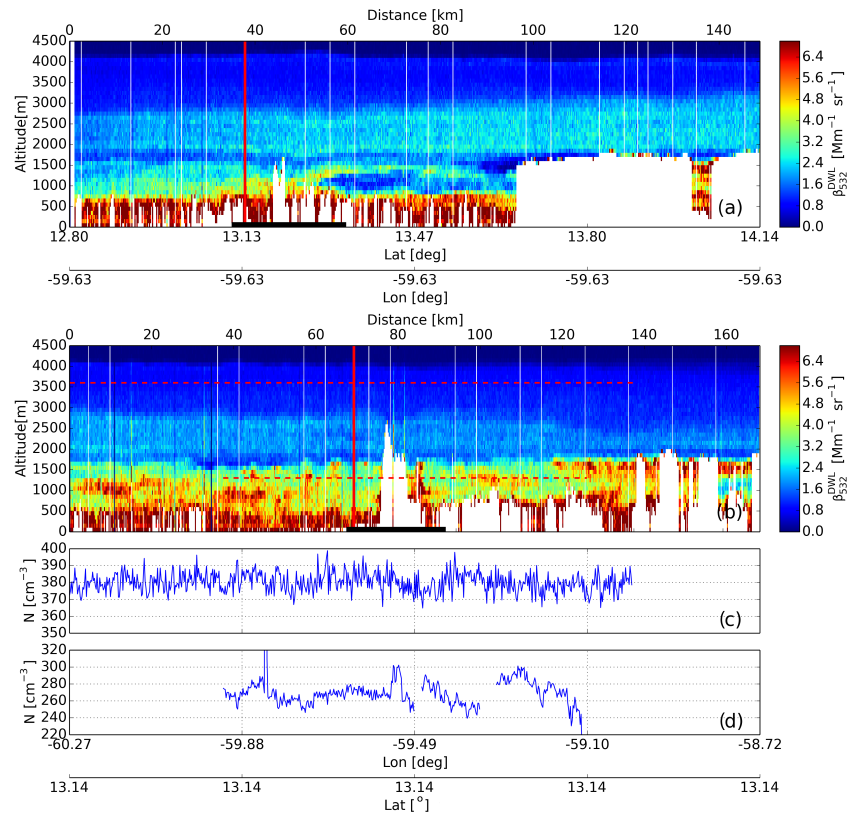

Figure 13. (a) Retrieved backscatter coefficient by the DWL as a function of the latitude and longitude from leg 1, together with the latitude at which legs 2, 3 and 4 were flown (solid line, red). (b) Retrieved backscatter coefficient by the DWL as a function of the latitude and longitude from leg 2, the intersection position with the $1 \mathrm{st}$ leg (solid line, red) and the legs 3 and 4 are shown (dashed line., red). (c, d) In situ CPC measurements corresponding to the legs 3 and 4 . The white colour indicates regions where no atmospheric signal is available (e.g., below clouds, unseeded laser operation). Barbados indicated in both plots with a horizontal solid black line.

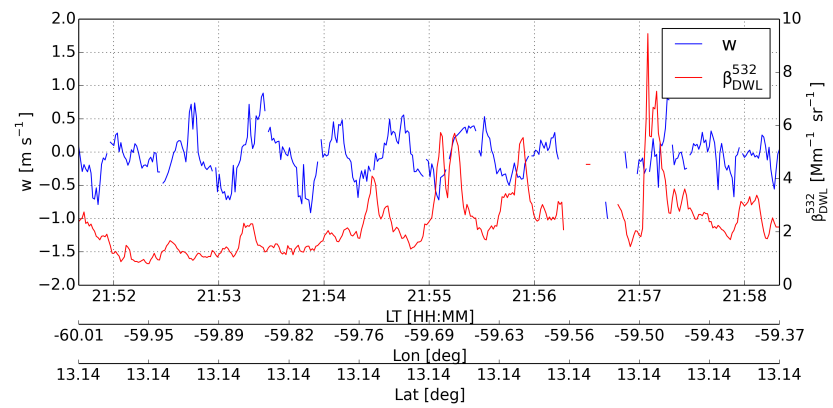

Figure 14. Retrieved backscatter coefficient (red) and vertical wind speed (blue) on the lee side of Barbados during the flight of the 2nd leg at an altitude of $1600 \mathrm{~m}$. Due to the presence of clouds, data between 21:56 and 21:57 LT are missing.

The backscatter coefficient and vertical wind corresponding to the boundary where the waves were observed are displayed in Fig. 14. As for the previous case, a phase difference of $90^{\circ}$ is observed between both quantities, which is compatible with a no net flux condition. Although in this particular case this feature was already observed by in situ measurements in the previous case study, the shown mea- 

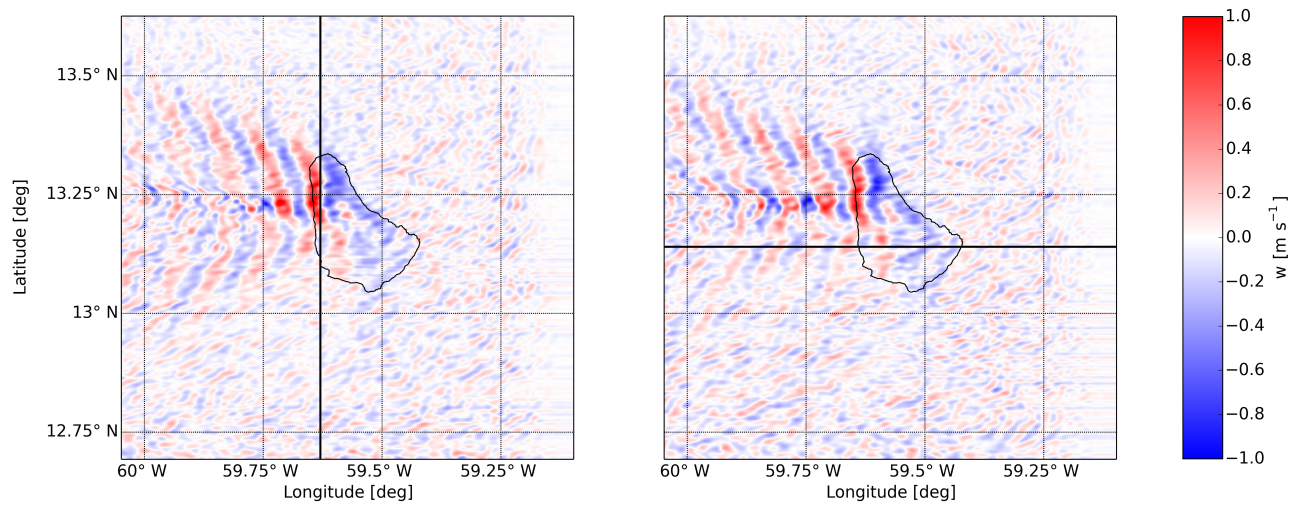

Figure 15. Vertical wind speed at $1975 \mathrm{~m}$ derived from the LES corresponding to 26 June at 20:00 LT (left panel) and 22:00 LT (right panel). The flight tracks corresponding to leg 1 (left) and 2 (right) are also indicated (solid, black).

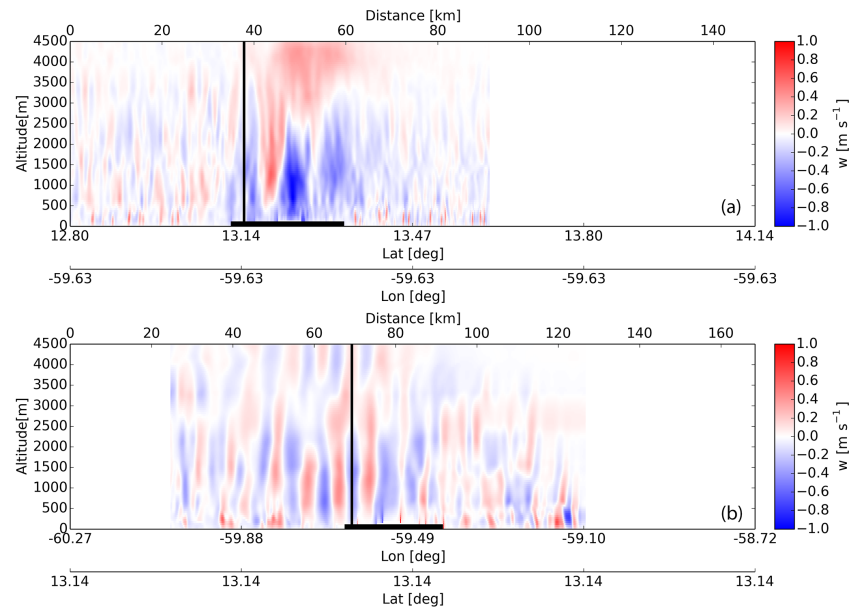

Figure 16. Vertical wind speed from the LES for 26 June at 20:00 LT for leg 1 (upper panel) and 22:00 LT for leg 2 (lower panel). The location of Barbados is indicated as a horizontal black segment, while the intersection between legs 1 and 2 is indicated with a vertical line.

surements provide an example of the possibilities opened up by the simultaneous retrieval of vertical wind and calibrated backscatter coefficient from a single instrument along a whole vertical transect. Based on the technique proposed by Engelmann et al. (2008), the simultaneous retrieval of backscatter coefficient and vertical wind can be used, under low humidity conditions, to retrieve aerosol vertical flux profiles. Dry atmospheric conditions are required in order to avoid the hygroscopic growth of aerosol particles, which otherwise would lead to a wrong flux estimation. The exact relative humidity threshold under which hygroscopic growth can be neglected varies according to the aerosol type. For the case of sea salt and desert dust, hygroscopic growth can be safely neglected for a relative humidity below $50 \%$ (e.g. Engelmann et al., 2008; Kaaden et al., 2008).

\subsubsection{Large-eddy simulations}

Large-eddy simulations are performed with the All Scale Atmospheric Model (ASAM, Jähn et al., 2015) for the Barbados area. The model setup is described in Jähn et al. (2016), where the focus of the analysis lies on island effects on boundary layer modification, cloud generation and vertical mixing of aerosols. In this study, the simulation results along the measurement tracks are first compared with the DWL observations in order to provide further validation of the model and setup. Then the whole simulation results are used to provide a broader perspective of the context within which the measurements took place.

For the simulations, a model domain with a spatial extent of $102.4 \times 102.4 \mathrm{~km}$ is chosen with Barbados located at the domain centre. The model top is at $5 \mathrm{~km}$ altitude. Grid spacings of $200 \mathrm{~m}$ (horizontally) and $50 \mathrm{~m}$ (vertically) are used and topographical data are obtained from the Consortium for Spatial Information (CGIAR-CSI) Shuttle Radar Topography Mission (SRTM) data set (http://srtm.csi.cgiar.org) at $200 \mathrm{~m}$ resolution. The highest elevation of Barbados is Mount Hillaby, $340 \mathrm{~m}$ above sea level. Due to the presence of a topographically structured island surface in the domain centre, the simulations are performed with open lateral boundaries.

In order to generate inflow turbulence consistent with the upstream marine boundary layer forcing, the newly developed turbulence generation method is applied. The model runs are initialised with nighttime radiosonde data of the considered day and are integrated from 02:00 to 22:00 LT. Further details on the setup and comparison with the DWL can be found in Jähn et al. (2016).

In order to allow a qualitative comparison of the results from the LES with the measurements from the DWL, plots of the simulated vertical wind speed on time periods similar to those corresponding to the measurements are presented in Figs. 15 and 16. Figure 15 shows two horizontal cuts of the vertical wind speed at 20:00 and 22:00 LT together with the 


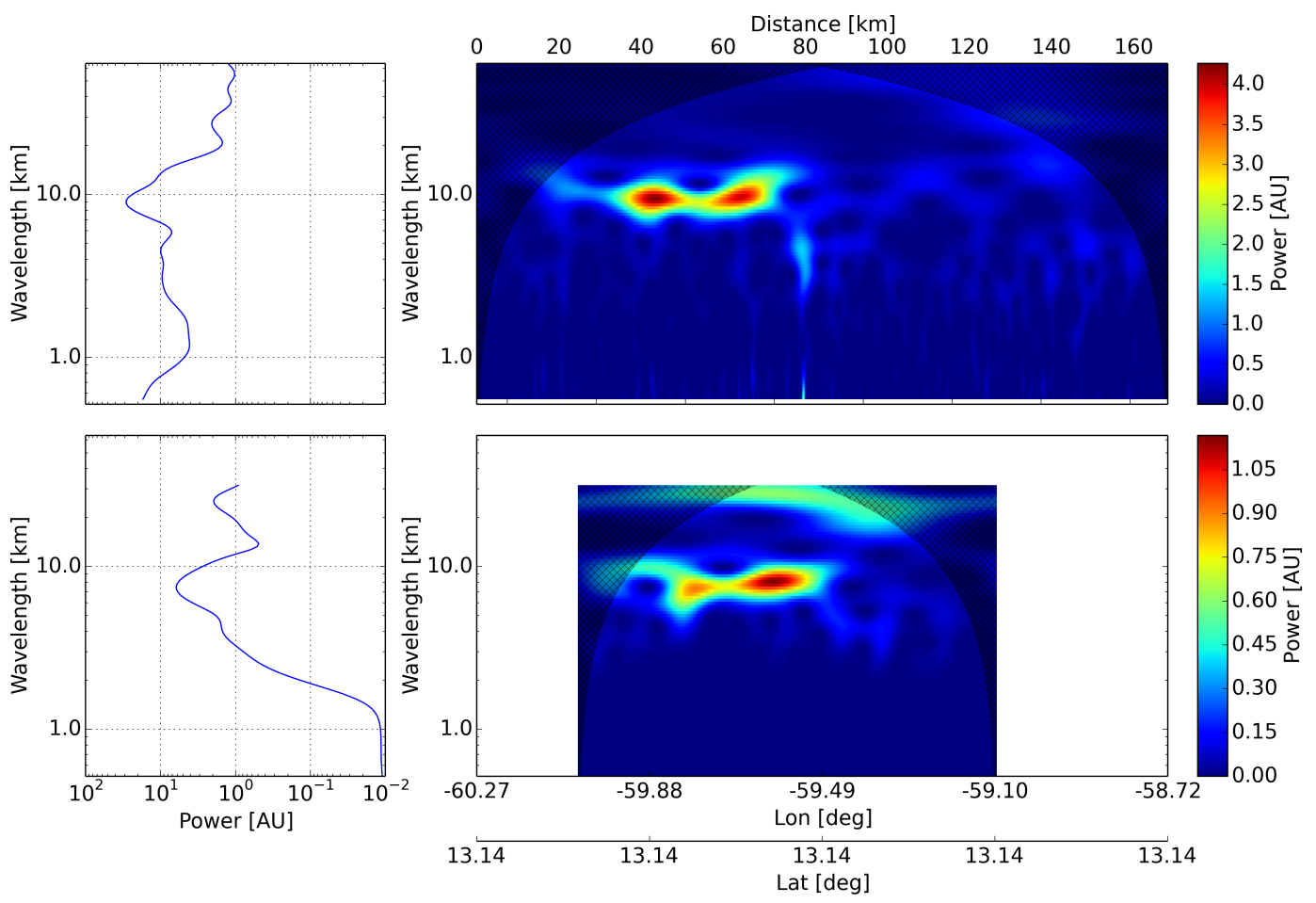

Figure 17. Wavelet analysis of the vertical wind corresponding to the 2 nd leg for the flight on 26 June derived from the DWL measurements (Fig. 11b) at $2000 \mathrm{~m}$ (upper panels) and derived from the LES (Fig. 16b) at $2000 \mathrm{~m}$ (lower panels). The hatched areas indicate the cone of influence. The left panels show the average power for each wavelength.

flight track of the Falcon corresponding to legs 1 and 2. The horizontal plane is located at an altitude of $1975 \mathrm{~m}$, coinciding with the temperature inversion observed by the in situ measurements and the maximum in the horizontal wind shear observed by the DWL, in situ and dropsonde measurements. Figure 16 displays the simulated vertical winds corresponding to the 1 st and 2 nd legs flown by the Falcon (indicated in Fig. 15). The horizontal scales of the plots were adjusted to simplify the comparison with the measurements presented in Fig. 11.

\subsubsection{Comparison of LES and DWL}

As can be seen in Figs. 15 and 16, the LES is able to reproduce the observations from the DWL. A limited coverage over Barbados due to the presence of convective clouds is compatible with the convective plumes observed in the simulations. Trapped waves with a wavelength and extension similar to the lidar observations can be recognized on the lee side of Barbados. The vertical cut presented in Fig. 16a shows an updraft above Barbados similar to the one shown in Figs. 11a, and 15a shows that the vertical cut is located along a wave crest. This simulation result provides support to the hypothesis presented in Sect. 4.1 to explain the strong updraft observed above Barbados during the first measurement leg.
A wavelet transform was applied to the measured and simulated vertical wind speed in order to provide a quantitative wavelength, amplitude and extension comparison of the simulated and measured trapped waves. The measured data were interpolated in the same way as described in Sect. 3, matching for this case, the spatial resolution of the LES $(200 \mathrm{~m})$. The results of the wavelet transforms are presented in Fig. 17.

According to the wavelet analysis, the wavelength of the measured waves is approximately $9 \mathrm{~km}$, while for the case of the LES the wavelength is approximately $7.5 \mathrm{~km}$. The difference can be attributed to different reasons such as small differences in the propagation direction of the waves. As mentioned before, the LES is initialised with a constant wind speed direction equal to $90^{\circ}$. This approximation can induce differences in the direction of propagation of the waves, which in turn induce differences in the apparent wavelength of the measurements for the same flight track.

While the amplitude of the simulated waves is quite similar at different altitudes, the DWL measurements show a maximum in the amplitude at approximately $2000 \mathrm{~m}$. This difference is evident from the results of the wavelet analysis, calculated at the altitude of this maximum in both cases. As explained in the previous section, the horizontal wind speed used for the initialization of the LES is assumed constant between 0.7 and $3 \mathrm{~km}$. Because this approximation neglects the strong shear measured at $2000 \mathrm{~m}$, a difference between the 
simulated and the measured vertical wind speed is expected at this altitude.

\section{Summary and conclusions}

In the first section of this work, a series of instrumental corrections required for the retrieval of vertical winds from airborne DWL measurements were presented. The difference of almost 2 orders of magnitude between the platform speed and the measured vertical wind speed, together with the varying aircraft orientation during the flight, transforms the retrieval of vertical winds in a challenging problem. Although no control of the lidar pointing direction was active during the vertical wind measurements, the use of horizontal wind from dropsondes and in situ measurements proved to be useful to partially compensate the effects of the horizontal wind component projection. The use of conical scanning pattern measurements and the recalculation of the lidar mounting angle based on the ground return speed and distance previous to the vertical wind measurements proved to be useful to reduce the systematic error, especially after a change in the flight altitude. The measurement uncertainties were estimated based on two different techniques. The estimated systematic error, based one measurement case, was $-0.05 \mathrm{~m} \mathrm{~s}^{-1}$, while the random error was between 0.1 and $0.16 \mathrm{~m} \mathrm{~s}^{-1}$ depending on the technique used for the estimation.

The described methods were applied to retrieve vertical winds corresponding to two SALTRACE research flights, one in the Cabo Verde region and a second one in Barbados. The measurements revealed the presence of island induced gravity waves in both cases. Vertical profiles of temperature, wind and humidity obtained from in situ and dropsonde measurements were used to calculate a Scorer parameter profile for each measurement case. The wavelength and the vertical extension of the trapped waves observed from the DWL measurements in the Cabo Verde case study were in coincidence with the retrieved Scorer parameter profile. The spatial extension, amplitude and wavelength retrieved from the in situ vertical wind measurements provided an independent validation for the DWL observation. A second independent observation of the particle number concentration provided an additional confirmation.

Although for the second case study the in situ measurement did not show the waves observed by the DWL in a previous leg, the results of the ASAM model support the lidar observations. The model was able to reproduce the generation of waves in the lee side of the island and provided a context to the lidar observations, which are limited to two dimensional vertical cuts. The amplitude and wavelength of the simulated waves were lower than the observed ones. This can be explained by the simplifications adopted in the horizontal wind profiles used to initialise the model, which did not reproduce the strong shears observed in the dropsondes and in situ measurements.

\author{
The Supplement related to this article is available online \\ at doi:10.5194/acp-16-4675-2016-supplement.
}

Acknowledgements. This work was funded by the Helmholtz Association under grant number VH-NG-606 (Helmholtz-HochschulNachwuchsforschergruppe AerCARE). The SALTRACE campaign was mainly funded by the Helmholtz Association, DLR, LMU and TROPOS. The SALTRACE flights on Cabo Verde were funded through the DLR-internal project VolcATS (Volcanic ash impact on the Air Transport System). DLR Falcon aircraft in situ data were processed by the DLR Flight Experiment. The first author thanks the German Academic Exchange Service (DAAD) for the financial support.

The article processing charges for this open-access

publication were covered by a Research

Centre of the Helmholtz Association.

Edited by: J. Schwarz

\section{References}

Alexander, M. J. and Grimsdell, A. W.: Seasonal cycle of orographic gravity wave occurrence above small islands in the Southern Hemisphere: Implications for effects on the general circulation, J. Geophys. Res.-Atmos., 118, 11589-11599, doi:10.1002/2013JD020526, 2013.

Amirault, C. and DiMarzio C.: Precision pointing using a dualwedge scanner, Appl. Opt., 24, 1302-1308, 1985.

Baik, J.: Response of a Stably Stratified Atmosphere to LowLevel Heating - An Application to the Heat Island Problem, J. Appl. Meteorol., 31, 291-303, doi:10.1175/15200450(1992)031<0291:ROASSA>2.0.CO;2, 1992.

Baines, J. and Hoinka, K. P.: Stratified Flow over Two-Dimensional Topography in Fluid of Infinite Depth: A Laboratory Simulation, J. Atmos. Sci., 42, 1614-1630, doi:10.1175/1520 0469(1985)042<1614:SFOTDT>2.0.CO;2, 1985.

Bluman, W. and Hart, J. E.: Airborne Doppler Lidar Wind Field Measurements of Waves in the Lee of Mount Shasta, J. Atmos. Sci., 45, 1571-1583, doi:10.1175/1520-0469(1988)045< 1571:ADLWFM>2.0.CO;2, 1988.

Bosart, B., Lee, W., and Wakimoto, R.: Procedures to Improve the Accuracy of Airborne Doppler Radar Data, J. Atmos. Ocean. Tech., 19, 322-339, doi:10.1175/1520-0426-19.3.322, 2002.

Chouza, F., Reitebuch, O., Groß, S., Rahm, S., Freudenthaler, V., Toledano, C., and Weinzierl, B.: Retrieval of aerosol backscatter and extinction from airborne coherent Doppler wind lidar measurements, Atmos. Meas. Tech., 8, 2909-2926, doi:10.5194/amt8-2909-2015, 2015.

Cui, Z., Blyth, A. M., Bower, K. N., Crosier, J., and Choularton, T.: Aircraft measurements of wave clouds, Atmos. Chem. Phys., 12, 9881-9892, doi:10.5194/acp-12-9881-2012, 2012.

De Wekker, S. F. J., Godwin, K. S., Emmitt, G. D., and Greco, S.: Airborne Doppler Lidar Measurements of Valley Flows in Complex Coastal Terrain, J. Appl. Meteorol. Clim., 51, 1558-1574, doi:10.1175/JAMC-D-10-05034.1, 2012. 
Durran, D. R.: Mountain waves and downslope winds, in: Atmospheric Process over Complex Terrain, edited by: Blumen, W., American Meteorological Society, Boston, 59-81, 1990.

Durran, D. R., Hills, M. O. G., and Blossey, P. N.: The Dissipation of Trapped Lee Waves. Part I: Leakage of Inviscid Waves into the Stratosphere, J. Atmos. Sci., 72, 1569-1584, doi:10.1175/JASD-14-0238.1, 2015.

Ehard, B., Kaifler, B., Kaifler, N., and Rapp, M.: Evaluation of methods for gravity wave extraction from middle-atmospheric lidar temperature measurements, Atmos. Meas. Tech., 8, 46454655, doi:10.5194/amt-8-4645-2015, 2015.

Emmitt, G. D. and Godwin, K.: Advanced airborne Doppler Wind Lidar signal processing for observations in complex terrain, Proc. SPIE 9246, Lidar Technologies, Techniques, and Measurements for Atmospheric Remote Sensing X, 924609, doi:10.1117/12.2068226, 2014.

Engelmann, R., Wandinger, U., Ansmann, A., Müller, D., Žeromskis, E., Althausen, D., and Wehner, B.: Lidar Observations of the Vertical Aerosol Flux in the Planetary Boundary Layer, J. Atmos. Ocean. Tech., 25, 1296-1306, doi:10.1175/2007JTECHA967.1, 2008.

Engelmann, R., Ansmann, A., Horn, S., Seifert, P., Althausen, D., Tesche, M., Esselborn, M., Fruntke, J., Lieke, K., Freudenthaler, V., and Groß, S.: Doppler lidar studies of heat island effects on vertical mixing of aerosols during SAMUM-2, Tellus B, 63, 448-458. doi:10.1111/j.1600-0889.2011.00552.x, 2011.

Frehlich, R.: Errors for Space-Based Doppler Lidar Wind Measurements: Definition, Performance, and Verification, J. Atmos. Ocean. Tech., 18, 1749-1772, 2001.

Georgelin, M. and Lott, F.: On the Transfer of Momentum by Trapped Lee Waves: Case of the IOP 3 of PYREX, J. Atmos. Sci., 58, 3563-3580, doi:10.1175/15200469(2001)058<3563:OTTOMB>2.0.CO;2, 2001.

Grewal, M. S., Weill, L. R., and Andrews, A. P.: Appendix C: Coordinate Transformations, in: Global Positioning Systems, Inertial Navigation, and Integration, Second Edn., John Wiley \& Sons, Inc., Hoboken, NJ, USA, 456-501, doi:10.1002/9780470099728.app3, 2007.

Henderson, S. W., Suni, P. J. M., Hale, C. P., Hannon, S. M., Magee, J. R., Bruns, D. L., and Yuen, E. H.: Coherent laser radar at $2 \mu \mathrm{m}$ using solid-state lasers, IEEE T. Geosci. Remote, 31, 4-15, 1993.

Jähn, M., Knoth, O., König, M., and Vogelsberg, U.: ASAM v2.7: a compressible atmospheric model with a Cartesian cut cell approach, Geosci. Model Dev., 8, 317-340, doi:10.5194/gmd-8317-2015, 2015.

Jähn, M., Muñoz-Esparza, D., Chouza, F., Reitebuch, O., Knoth, O., Haarig, M., and Ansmann, A.: Investigations of boundary layer structure, cloud characteristics and vertical mixing of aerosols at Barbados with large eddy simulations, Atmos. Chem. Phys., 16, 651-674, doi:10.5194/acp-16-651-2016, 2016.

Kaaden, N., Massling, A., Schladitz, A., Müller, T., Kandler, K., Schütz, L., Weinzierl, B., Petzold, A., Tesche, M., Leinert, S., Deutscher, C., Ebert, E., Weinbruch, S., and Wiedensohler, A.: State of mixing, shape factor, number size distribution, and hygroscopic growth of the Saharan anthropogenic and mineral dust aerosol at Tinfou, Morocco, Tellus, 61, 51-63, doi:10.1111/j.1600-0889.2008.00388.x, 2008.

Kavaya, M. J., Beyon, J. Y., Koch, G. J., Petros, M., Petzar, P. J., Singh, U. N., Trieu, B. C., and Yu, J.: The Doppler Aerosol Wind
(DAWN) Airborne, Wind-Profiling Coherent-Detection Lidar System: Overview and Preliminary Flight Results, J. Atmos. Ocean. Tech., 31, 826-842, doi:10.1175/JTECH-D-12-00274.1, 2014.

Käsler, Y., Rahm, S., Simmet, R., and Kühn, M.: Wake measurements of a multi-MW wind turbine with coherent long-range pulsed doppler wind lidar, J. Atmos. Ocean. Tech., 27, 15291532, 2010.

Kiemle, C., Ehret, G., Fix, A., Wirth, M., Poberaj, G., Brewer, W. A., Hardesty, R. M., Senff, C., and LeMone, M. A.: Latent Heat Flux Profiles from Collocated Airborne Water Vapor and Wind Lidars during IHOP_2002, J. Atmos. Ocean. Tech., 24, 627-639, doi:10.1175/JTECH1997.1, 2007.

Kiemle, C., Wirth, M., Fix, A., Rahm, S., Corsmeier, U., and Di Girolamo, P.: Latent heat flux measurements over complex terrain by airborne water vapour and wind lidars, Q. J. Roy. Meteor. Soc., 137, 190-203, doi:10.1002/qj.757, 2011.

Kirkwood, S., Mihalikova, M., Rao, T. N., and Satheesan, K.: Turbulence associated with mountain waves over Northern Scandinavia - a case study using the ESRAD VHF radar and the WRF mesoscale model, Atmos. Chem. Phys., 10, 3583-3599, doi:10.5194/acp-10-3583-2010, 2010.

Köpp, F., Rahm, S., and Smalikho, I.: Characterization of Aircraft Wake Vortices by 2- $\mu$ m Pulsed Doppler Lidar, J. Atmos. Ocean. Tech., 21, 194-206, 2004.

Kühnlein, C., Dörnbrack, A., and Weissmann, M.: HighResolution Doppler Lidar Observations of Transient Downslope Flows and Rotors, Mon. Weather Rev., 141, 3257-3272, doi:10.1175/MWR-D-12-00260.1, 2013.

O'Connor, E. J., Illingworth, A. J., Brooks, I. M., Westbrook, C. D., Hogan, R. J., Davies, F., and Brooks, B. J.: A Method for Estimating the Turbulent Kinetic Energy Dissipation Rate from a Vertically Pointing Doppler Lidar, and Independent Evaluation from Balloon-Borne In Situ Measurements, J. Atmos. Ocean. Tech., 27, 1652-1664, doi:10.1175/2010JTECHA1455.1, 2010.

Prospero, J. M.: Long-range transport of mineral dust in the global atmosphere: Impact of African dust on the environment of the southeastern United States, P. Natl. Acad. Sci. USA, 96, 33963403, 1999.

Prospero, J. M. and Mayol-Bracero, O. L.: Understanding the Transport and Impact of African Dust on the Caribbean Basin, B. Am. Meteorol. Soc., 94, 1329-1337, doi:10.1175/BAMS-D12-00142.1, 2013

Rahm, R., Smalikho, I., and Köpp, F.: Characterization of Aircraft Wake Vortices by Airborne Coherent Doppler Lidar, J. Aircraft, 44, 799-805, 2007.

Reitebuch, O.: Wind Lidar for Atmospheric Research, in: Atmospheric Physics, edited by: Schumann, U., Springer, Berlin, Heidelberg, 487-507, 2012.

Reitebuch, O., Werner, C., Leike, I., Delville, P., Flamant, P. H., Cress, A., and Engelbart, D.: Experimental validation of wind profiling performed by the airbone $10-\mu \mathrm{m}$ heterodyne Doppler Lidar WIND, J. Atmos. Ocean. Tech., 18, 1331-1344, 2001.

Reitebuch, O., Volkert, H., Werner, C., Dabas, A., Delville, P., Drobinski, P., Flamant, P. H., and Richard, E.: Determination of air flow across the Alpine ridge by a combination of airborne Doppler lidar, routine radio-sounding, and numerical simulation, Q. J. Roy. Meteor. Soc., 129, 715-728, 2003. 
Sachsperger, J., Serafin, S., and Grubišić, V.: Lee Waves on the Boundary-Layer Inversion and Their Dependence on Free-Atmospheric Stability, Front. Earth Sci., 3, 70, doi:10.3389/feart.2015.00070, 2015.

Savijärvi, H. and Matthews, S.: Flow over Small Heat Islands: A Numerical Sensitivity Study, J. Atmos. Sci., 61, 859-868, doi:10.1175/1520-0469(2004)061<0859:FOSHIA>2.0.CO;2, 2004.

Scorer, R. S.: Theory of waves in the lee of mountains, Q. J. Roy. Meteor. Soc., 75, 41-56, doi:10.1002/qj.49707532308, 1949.

Smith, R. B.: Linear theory of stratified hydrostatic flow past an isolated obstacle, Tellus, 32, 348-364, 1980.

Smith, R. B., Skubis, S., Dolye, J. D., Broad, A., and Volkert, H.: Mountain waves over Mont Blanc: Influence of a stagnant boundary layer, J. Atmos. Sci., 59, 2073-2092, 2002.

Torrence, C. and Compo, G. P.: A practical guide to wavelet analysis, B. Am. Meteorol. Soc., 79, 61-78, 1998.
Vosper, S. B.: Inversion effects on mountain lee waves, Q. J. Roy. Meteor. Soc., 130, 1723-1748, doi:10.1256/qj.03.63, 2004.

Weinzierl, B., Sauer, D., Esselborn, M., Petzold, A., Veira, A., Rose, M., Mund, S., Wirth, M., Ansmann, A., Tesche, M., Groß, S., and Freudenthaler, V.: Microphysical and optical properties of dust and tropical biomass burning aerosol layers in the Cape Verde region - an overview of the airborne in situ and lidar measurements during SAMUM-2, Tellus B, 63, 589-618, doi:10.1111/j.16000889.2011.00566.x, 2011.

Weissmann, M., Busen, R., Dörnbrack, A., Rahm, S., and Reitebuch, O.: Targeted observations with an airborne wind lidar, J. Atmos. Ocean. Tech., 22, 1706-1719, 2005.

Woods, B. K. and Smith, R. B.: Energy Flux and Wavelet Diagnostics of Secondary Mountain Waves, J. Atmos. Sci., 67, 37213738, doi:10.1175/2009JAS3285.1, 2010. 